\author{
Report No. BMI-1306 \\ C-83 - Reactors - Special Features \\ of Military Package \\ Power Reactors \\ (M-3679, 22nd Ed.)
}

Contract No. W-7405-eng-92

\title{
FURTHER STUDIES WITH THE \\ GCRE CRITICAL ASSEMBLY
}

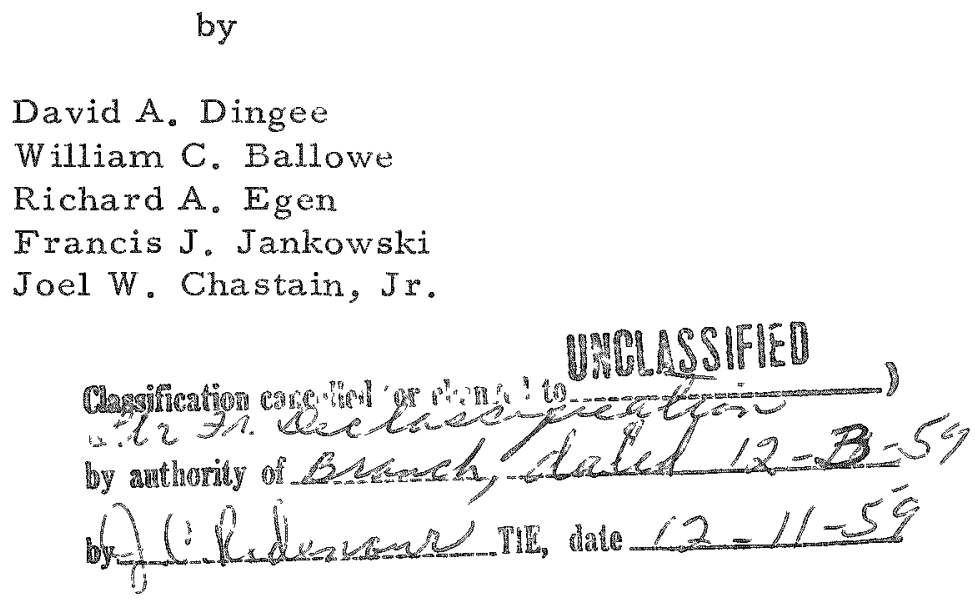

December 29, 1958

\section{RESTRICTED DATA}

This document contains pestricted data as defined in the Atomic Energy Act of 1954, Its transmitcal or disclosure of its contents in any manner to an unauthorised person is prohibited.

BATTELLE MEMORIAL INSTITUTE $505 \mathrm{King}$ Avenue Columbus 1, Ohio

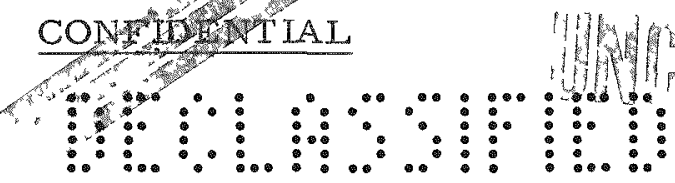




\section{DISCLAIMER}

This report was prepared as an account of work sponsored by an agency of the United States Government. Neither the United States Government nor any agency Thereof, nor any of their employees, makes any warranty, express or implied, or assumes any legal liability or responsibility for the accuracy, completeness, or usefulness of any information, apparatus, product, or process disclosed, or represents that its use would not infringe privately owned rights. Reference herein to any specific commercial product, process, or service by trade name, trademark, manufacturer, or otherwise does not necessarily constitute or imply its endorsement, recommendation, or favoring by the United States Government or any agency thereof. The views and opinions of authors expressed herein do not necessarily state or reflect those of the United States Government or any agency thereof. 


\section{DISCLAIMER}

Portions of this document may be illegible in electronic image products. Images are produced from the best available original document. 
ABSTRACT . • . . . . • . . . . . . . . . . . 5

INTRODUCTION

Background . . . . . . . . . . . . . . . . . . 5

Scope of the Additional Studies . . . . . . . . . . . . . . . . . 6

EXPERIMENTAL PROCEDURES • . . • . . . . . . . . . . . . 9

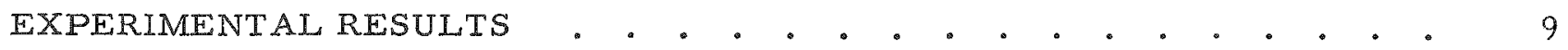

Lead-Reflected Core . . . . . . . . . . . . . . . . . . 9

Critical Core Configuration . . . . . . . . . . . . . . 9

Reactivity Worth of Axial Reflector Materials . . . . . . 10

Reactivity Worth of Mock-Up Blade Guides . . . . . . . . 11

Power Distortion Caused by Mock-Up Blade Guides . . . . . . 11

Lead-Reflected Core - Modified Fuel Loading . . . . . . . . . 15

Critical Core Configuration . . . . . . . . . . . . 15

Reactivity Worth of Peripheral Fuel Elements . . . . . . . 16

Estimated Worth of Fuel Additions . . . . . . . . . 16

Migration-Area Measurements . . . . . . . . . . 16

Flux Measurements . . . . . . . . . . . . . . 17

Thermal Utilization Measurements . . . . . . . . . 21

Lead-Reflected Core - Modified Steel Content . . . . . . . . . 21

Critical Core Configuration . . . . . . . . . . . . . 21

Reactivity Worth of Peripheral Fuel Elements . . . . . . . 23

Estimated Worth of Stainless Steel Addition . . . . . . . . 23

Uniform Radial Power Distribution Core . . . . . . . . . . . 23

Critical Core Configuration . . . . . . . . . . . 26

Power-Distribution Measurements . . . . . . . . . . 26

Flux-Distribution Measurements . . . . . . . . . . . 29

Thermal Utilization Measurements . . . . . . . . . 29

SUMMARY •. •. . . . . . . . . . . . . . . . . 34 
FURTHER STUDIES WITHI THE GCRE CRITICAL ASSEMBLY

\author{
David A. Dingee, William C. Ballowe, Richard A. Egen, \\ F. J. Jankowski, and Joel W. Chastain, Jr.
}

Further engineering and physics data to aid in constructing GCRE-I were obtained in critical-assembly studies. Four major experiments were performed to investigate:

(1) The effect on reactivity caused by changes in axial reflector materials.

(2) The effect on reactivity and the power perturbation caused by fast safety control-blade guides

(3) The effect of changes in fuelelement material composition.

(4) The effect of changes in fuel-element spacing designed to produce uniform radial powerogeneration rates.

All studies were performed with a 4-in.-thich lead reflector at the core perimeter.

Axial-reflector-material studies employed combinations of aluminum and steel reflectors. The reactivity worth of a 2-3'tin.-thich steel reflector was +0.414 per cent $\Delta k / k$ compared with 0.175 per cent $\Delta k, k$ for a similar aluminum reflector.

The perturbation in the flux distribution caused by the safety-blade guides was localized, and affected only the regions immediatelv adjacent to the guides. The combined reactivity worth of two guides u'as -0.281 per cent $\Delta l / k$.

Fuel-element material compositions u'ere changed by separate additions of fuel and stainless steel. An increase in uranium loading from an average value of 303 a to $40 \mathrm{Ag}$ per element would provide, based on extrapolations from experimental dat a, a reactivity of about 1.5 per cent $\Delta k$ k in a 56-element core. $4 n$ increase in steel from $1708 \mathrm{~g}$ to $2093 \mathrm{~g}$ per element decreased the core reactivity by about 1.1 per cent $\$ k^{\prime} k$.

4 change in fuel-element spacing reduced the ratio of maximum to average pouce generaition from 1.46 to 1.24 .

\title{
INTRODUCTION
}

Background

Aerojet-General Corporation is develuping a gas-cooled transportable nuclear power plant for the Army Reactors Branch of the Atomic Energy Commission. The program of development includes the operation of a test reactor, Gas Cooled Reactor Experiment-1 (GCRE-1), at the National Reactor Testing Station in Idaho. To provide data in developing GCRE-1, critical-assembly experiments have been in progress at Battelle's Nuclear Research Center during the past year.

After about 8 months of experimentation Batte1le is sued a report, "GCRE CriticalAssembly Studies", BMI-1288, summarizing the initial critical experiments. The results of these experiments were used in developing the reactor configuration for GCRE-1. The report indicates the steps taken in this development by describing the various core configurations studied and the experiments undertaken with each core.

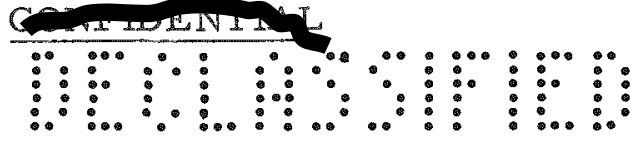


Four different cores were investigated. All utilized the fuel-element assembly shown in Figure 1. For most of the experiments a 5-in. -wide mock-up burnablepoison foil $10.12 \mathrm{mil}$ of cadmium plated onto 15 -mil-thick steel foil) was wrapped on the insulation-liner tube. The center of the foil was $1 \mathrm{in}$. above the horizontal midplane of the fuel. In all the cores studied, the fuel-elument lattice was hexagonal, as illustrated in Figure 2.

The order in which the core contigurations were assembled represents an approach toward a core for GCRE-1 which will have sufficient excess reactivity to meet power, lifetime, and operating requirements but which can be adequately shut down when the coolant regions are flooded for fuel-element removal. The first configuration taken critical was the Experimental Core consisting of an array of fuel elements without the mock-up burnable-poison foil. This core provided immediate data to aid in "normalizing" the physics calculations. Next the cadmium foil was added to the fuel elements to form the Clean Core. This was a good mock-up of the GCRE design at the time of the experiments. The core was modified to allow for greater excess reactivity, smaller size, and improved shielding by adding a 4 -in, -thick lead reflector at the perimeter (see Figure 2). The resulting configuration was termed the Lead-Reflected Core. It is a close mock-up of the current GCRE-1 design. The final core assembly studied was the Simulated-Flooded Core. This configuration simulated the conditions which will prevail when the upper gas plenum is removed for exchanging fuel elements in the GCRE -1 and all regions of the fuel elements are flooded with water (mineral oil was used to simulate water in the experiments). The control system was evaluated in this core configuration.

After the conclusion of this initial phase, Aerojet-General Corporation requested that additional studies be undertaken. These studies were to provide specific data pertinent to GCRE-1 operations and information to aid in optimizing and developing advanced concepts of GCRE-1.

\section{Scope of the Additional Studies}

Four major experiments have been pexformed since BMI-1288 was issued:

(1) Investigation of changes in axial reflector materials

(2) Measurements of the reactivity effect and power distortion caused by fast safety control-blade guides

(3) Evaluation of the effect of changes in the fuel-element material composition

(4) Investigation of a fuel-element distribution designed to produce uniform radial power-generation rates.

Items (1) and (2) were intended to evaluate design problems which have arisen in

GCRE-1. Items (3) and (4) may find application in advanced concepts of GCRE-1 or in modifying GCRE-1, if time schedules permil.

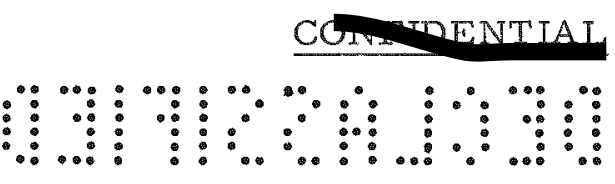




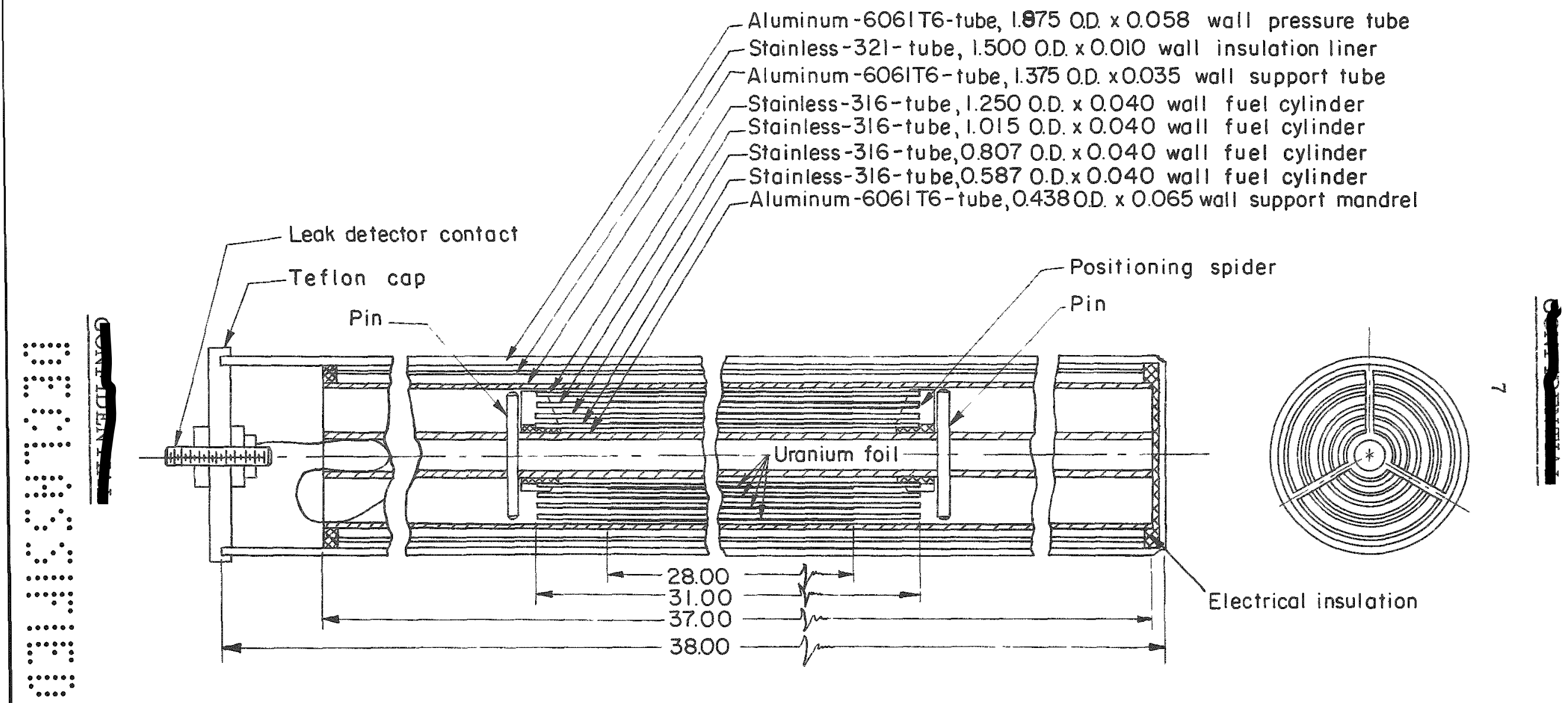

FIGURE 1. FUEL-ELEMENT ASSEMBLY

Burnable poison not shown. 


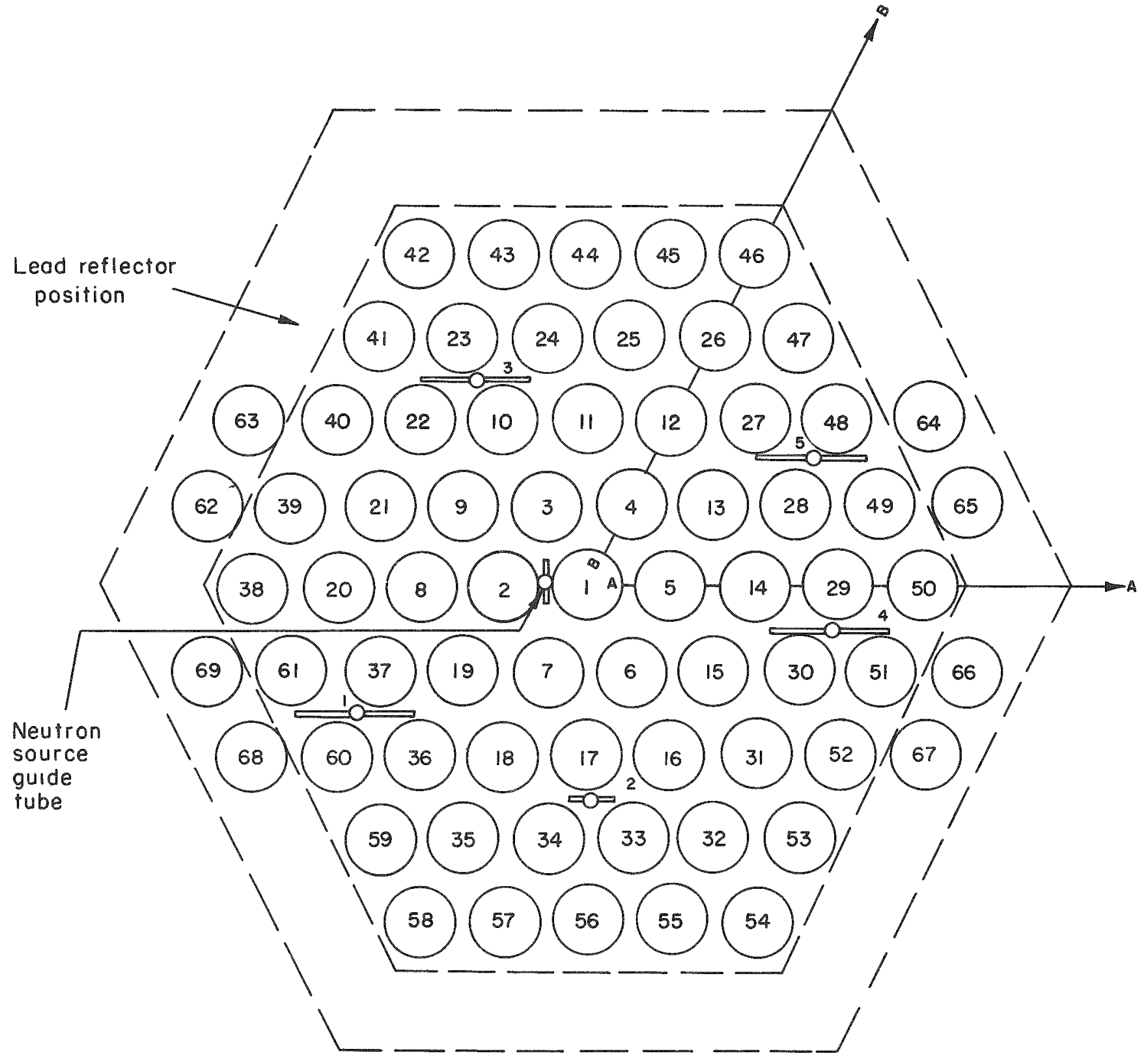

FIGURE 2. GCRE-1 CRITICAL-ASSEMBLY CORE NOMENCLATURE

Fuel-element position numbers are given. Criticalassembly control-rod positions are denoted by numbers at the appropriate locations between fuel elements. Radii $A A$ and $B B$ were used for flux- and powerdistribution measurements. 


\section{EXPERIMENTAL PROCEDURES}

A complete description of the critical assembly and associated instrumentation is given in BMI-1288. The specific procedures used in obtaining data are also given in that report. No changes in these procedures were made for the present experiments.

\section{EXPERIMENTAL RESULTS}

In reporting the research the reactor core configuration for each experiment will bo described and then the experimental arrangcments and results will be given.

In the present studies, Items (1) and (2) listed in "Scope of the Additional Studies" were done with a core configuration termed the Lead-Reflected Core. The studies with modified fuel elements, Item (3), were done with modifications of the Lead-Reflected Core. Item (4) involves a new core configuration which is termed the Uniform Radial Power-Distribution Core. Each of these configurations is described and the results of the experiments conducted with each given in a separate section of this report.

\section{Lead-Reflected Core}

The Lead-Reflected Core was composed of a hexagonal annulus of lead 4 in. thick surrounding 61 fuel-element positions. The lead reflector was $24 \mathrm{in}$. high and centered axially on the active portion of the fuel (which is $28 \mathrm{in.high}$ ) and was about $1 / 2 \mathrm{in}$. from the peripheral fuel elements.

\section{Critical Core Configuration}

The Lead-Reflected Core was critical with 56 fuel elements arranged as shown in Figure 3. The core contained $17,093 \mathrm{~g}$ of uranium-235 and had an excess reactivity of 0.383 per cent $\Delta \mathrm{k} / \mathrm{k}$. This figure compares with a previous determination of 0.495 per cent excess reported in BMI-1288. The difference is believed to be due to a combination of small effects which arosu in reconstructing the core from the SimulatedFlooded Core configuration. The Simulated-Flooded Core experiments reported in BMI-1288 were performed with all the elements filled with mineral oil. Reconstruction of the Lead-Reflected Core entailed completely disassembling all the elements, cleaning, and reassembling them. 


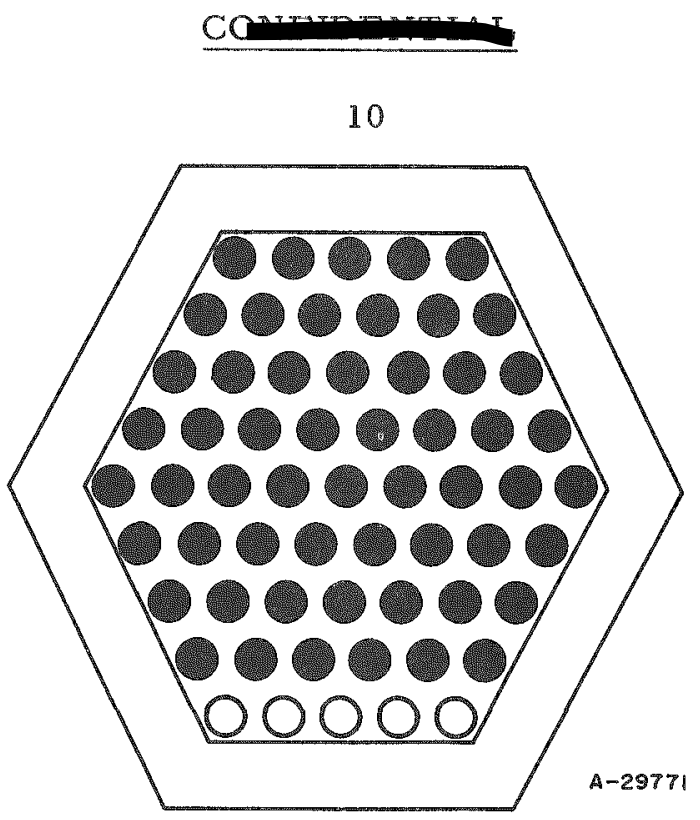

FIGURE 3. INITIAL CRITICAL CONFIGURATION IN LEAD-REFLECTED CORE

56 fuel elements.

Reactivity Worth of Axial Reflector

Materials

The upper axial reflector of the GCRE critical as sembly is normally composed of two 1-1/4-in.-thick aluminum support plates and a 1/4-in. -thick positioning plate. In order to investigate the worth of other materials the aluminum support plates (1) were replaced by air, (2) were replaced by a $2-3 / 4$-in. thick plate of steel, or (3) were used with an additional 2-3/4-in. -thick steel plate over them (i.e., a double axial reflector). The results of these experiments are given in Table 1.

\section{TABLE 1. EXPERIMENTAL RESULTS OF UPPER-AXIAL-REFLECTOR MATERIAL STUDIES}

\begin{tabular}{lccc}
\hline $\begin{array}{c}\text { Upper Axial } \\
\text { Reflector Material }\end{array}$ & $\begin{array}{c}\text { Number of } \\
\text { Fuel Elements } \\
\text { in the Core }\end{array}$ & $\begin{array}{c}\text { Excess Reactivity, } \\
\text { per cent } \Delta \mathrm{k} / \mathrm{k}\end{array}$ & $\begin{array}{c}\text { Reactivity Worth of } \\
\text { Reflector Material, } \\
\text { per cent } \Delta \mathrm{k} / \mathrm{k}\end{array}$ \\
\hline Void & 56 & 0.208 & $0.000(\mathrm{a})$ \\
Aluminum & 56 & 0.383 & 0.175 \\
Steel & 55 & 0.230 & $0.414(\mathrm{~b})$ \\
Aluminum and steel & 55 & 0.263 & 0.447 (b) \\
\hline \hline
\end{tabular}

(a) Void is used as a basis for material worths.

(b) Based on a determined worth of an element added to the cure perimeter of 0.392 per cent $\Delta \mathrm{k} / \mathrm{k}$. 
It is interesting to compare results obtained in earlier experiments with the Experimental Core configuration (a configuration of elements without a burnable poison and without a lead reflector) with those given in Table 1. For example, it was found that a 1.97 -in. -thick water reflector was worth 0.37 per cent $\Delta k / k$. Also, the worth of displacing the aluminum reflector $2 \mathrm{in}$. upward from the core was found to be 0.038 per cent $\Delta \mathrm{k} / \mathrm{k}$, or about one-fifth its total worth. If axial reflector-worth comparisons are made directly in the two core configurations, then it appears that the effect of the steel reflector is comparable with water. Furthermore, it is to be expected that there would be a reduction in the worth of steel when it is displaced to a position above the aluminum (treating aluminum and steel as independent reflectors).

\section{Reactivity Worth of Mock-Up Blade Guides}

GCRE-1 will use two fast safety control blades. Each of these will be supported in stainless steel guides which penetrate the core at all times. The reactivity effect of these guides was investigated by inserting stainless steel mock-up guides in the critical assembly as shown in Figure 4.

The combined worth of the two guides was found to be -0.281 per cent $\Delta k / k$.

Power Distortion Caused by Mock-Up

\section{Blade Guides}

To study the perturbation in the power distribution caused by the mock-up blade guides, measurements were made in Fuel-Element Positions 5, 27, 29, and 37 (shown on Figure 4). Catcher foils were located axially along the outer fuel cylinders of the se elements. These foils were placed on the sides facing the front and back of the core (see Figure 4). In the vicinity of the mock-up guides the foils were placed on 1/2-in. centers; at other axial regions the foils were 1 in. on center. Data were taken with the mock-up blade guides both in and out of the core.

The results of these measurements are given in Figures 5 and 6 . Figure 5 shows the perturbation in the power distribution in elements adjacent to one guide. Figure 6 shows the corresponding perturbation in a fuel element influenced by two blade guides (Position 5 includes the condition where a blade guide ends adjacent to it).

In general the distortion may be considered as a local effect. Since it occurs only on the side of the element facing the guide mock-ups, the effect exists axially only in the vicinity of the blade guides. However, the fuel element in Position 5 faces the tip of one of the guide mock-ups. At the tip a piece of steel holds the top and bottom guide pieces together (note Figure 4) and over this entire region the power is depressed. Even this element shows little power distortion on the side away from the guide mock-up.

An axial power plot obtained for Position 27 verified that the effect of the guide mock-ups did not extend beyond the row of elements immediately adjacent to them.

The difference between the relative magnitudes of the power levels measured at the front and back sides of the fuel cylinders is a result of the power-level gradient.

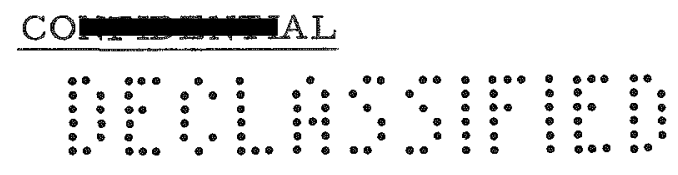




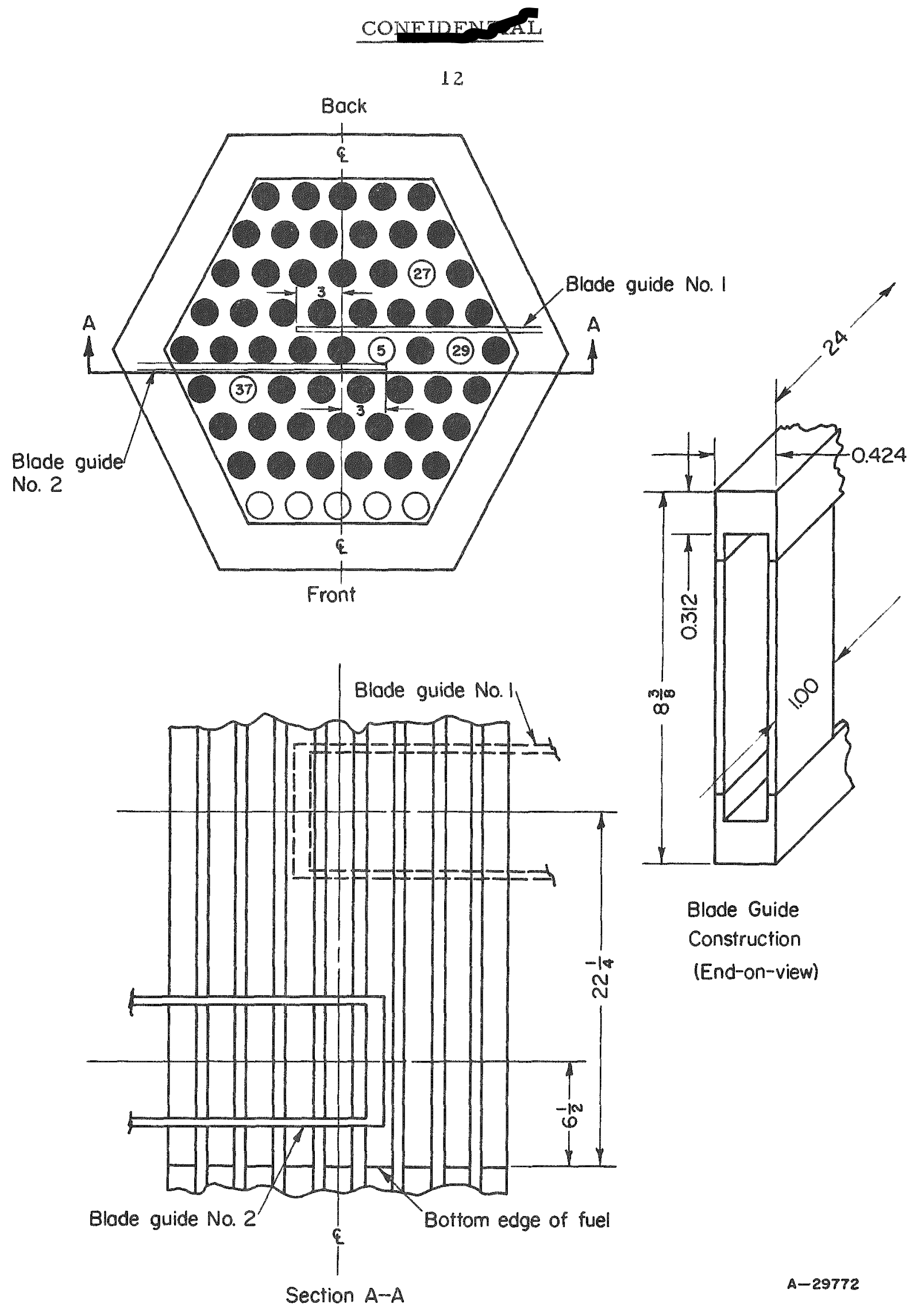

FIGURE 4. LOCATION AND CONSTRUCTION OF MOCK-UP BLADE GUIDES IN LEAD-REFLECTED CORE

COATTIOTNRTIAL

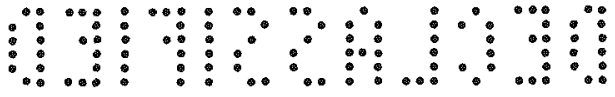




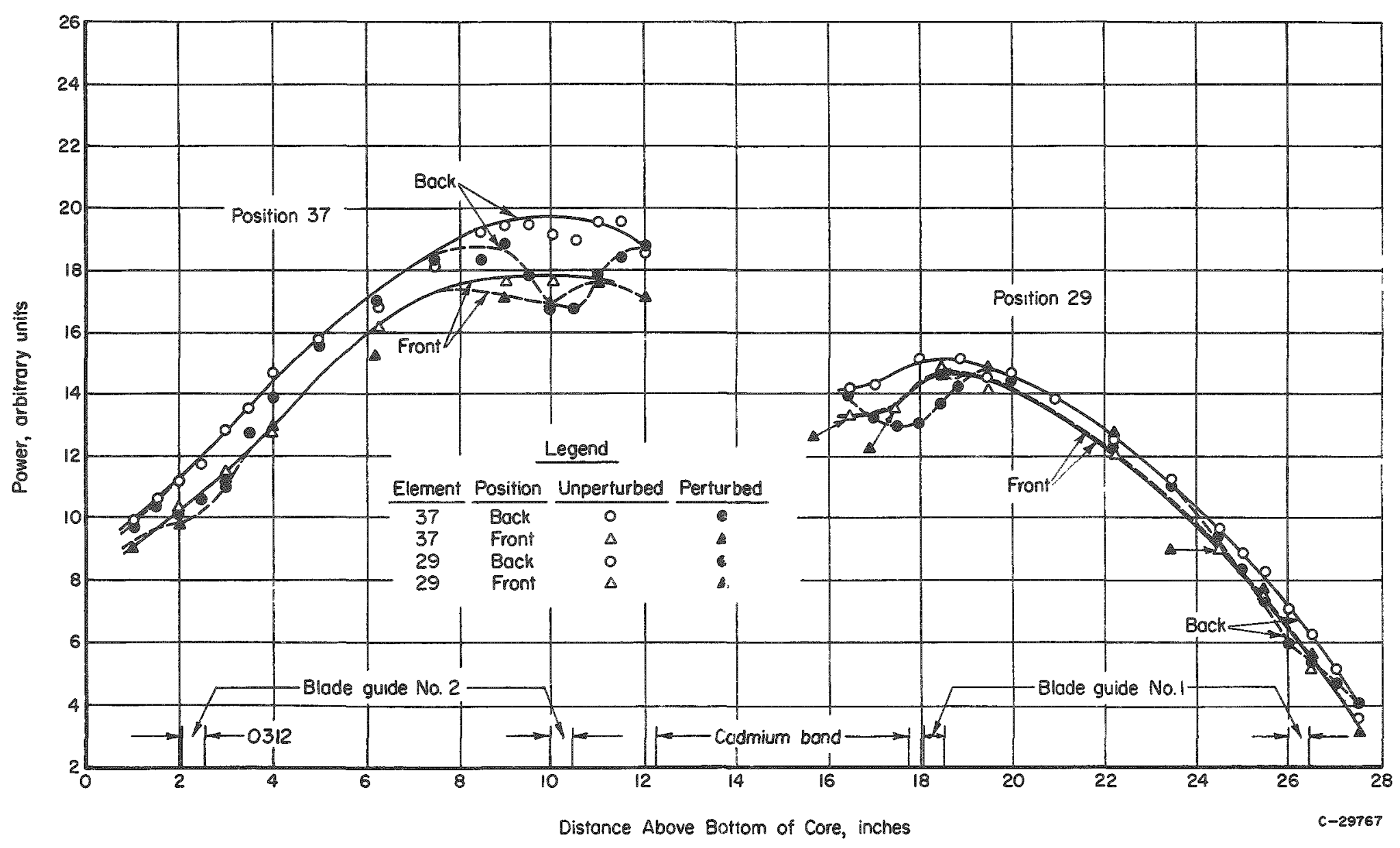

FIGURE 5. POWER DISTORTION IN VICINITY OF MOCK-UP BLADE GUIDES

Data obtained using catcher foils on outer fuel cylinder of elements in indicated core positions. 


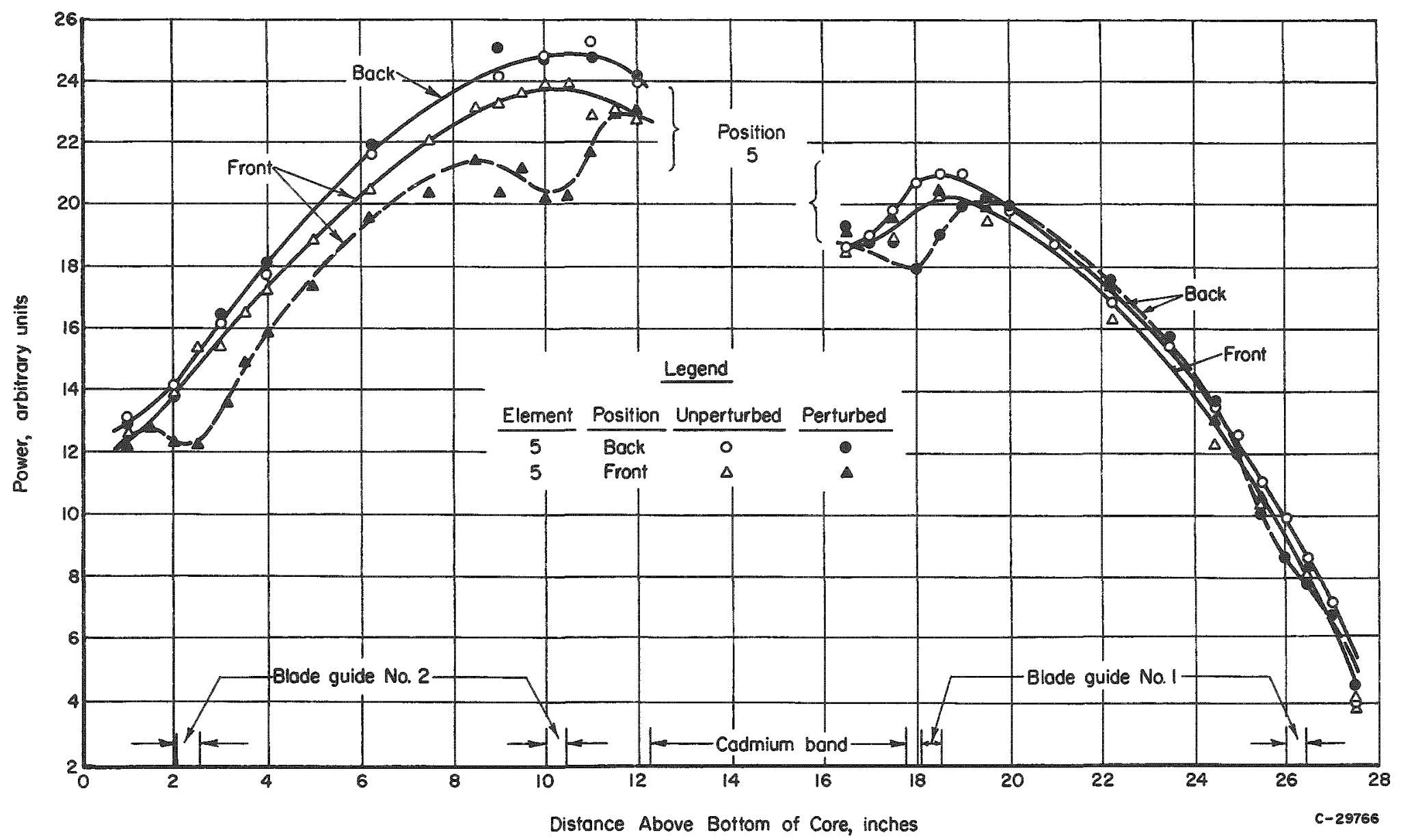

FIGURE 6. POWER DISTRIBUTION IN VICINITY OF MOCK-UP BLADE GUIDES

Data obtained using catcher foils on outer fuel cylinders of elements in indicated core positions. 


\section{Lead-Reflected Core - Modified Fuel Loading}

The Lead-Reflected Core was modified by adding fuel to each of the elements. The locations of the reflector and of the fuel elements were not changed. This condition provides normalization data for calculations concerning fuel concentrations and will find application if major changes in the fuel material are considered.

The fuel was added to each of the four fuel cylinders in an element by wrapping on an additional layer of 1 -mil-thick uranium-235 foil. The total fuel content of each element was increased from about $303 \mathrm{~g}$ to $404 \mathrm{~g}$ of uranium- 235 .

\section{Critical Core Configuration}

The Lead-Reflected Core with added fuel was critical with 47 fuel elements arranged as shown in Figure 7. The core contained 19,003 g of uranium-235 and an excess reactivity of 0.384 per cent $\Delta k / k$.

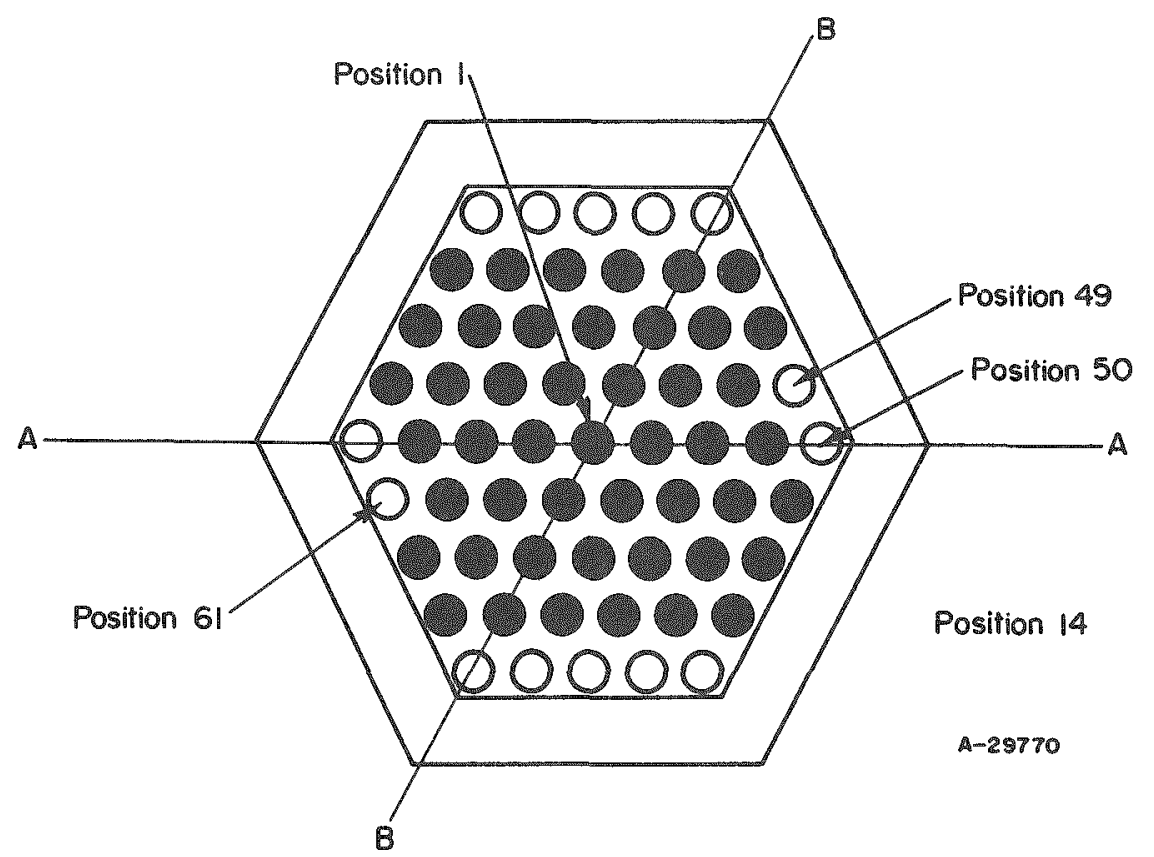

FIGURE 7. INITIAL CRITICAL CONFIGURATION IN LEAD-REFLECTED CORE MODIFIED WITH ADDITIONAL URANIUM-235

47 fuel elements. 
Reactivity Worth of Peripheral Fuel

Elements

During the experiments modified fuel elements $(404 \mathrm{~g})$ were added to Positions 49 and 61 in one experiment and to Position 50 in a second experiment to evaluate the worth of peripheral fuel elements. Table 2 gives the worth of these additions.

TABLE 2. WORTH OF FUEL-ELEMENT ADDITIONS TO THE LEAD-REFLECTED CORE MODIFIED BY FUEL ADDITIONS

\begin{tabular}{cccc}
\hline $\begin{array}{c}\text { Number of } \\
\text { Fuel Elements }\end{array}$ & $\begin{array}{c}\text { Fuel } \\
\text { Inventory, g }\end{array}$ & $\begin{array}{c}\text { Excess Reactivity, } \\
\text { per cent } \Delta \mathrm{k} / \mathrm{k}\end{array}$ & $\begin{array}{c}\text { Element } \\
\text { Worth, } \\
\text { per cent } \Delta \mathrm{k} / \mathrm{k}\end{array}$ \\
\hline 47 & 19,003 & 0.384 & \\
49 & 19,808 & 1.425 & 0.520 \\
50 & 20,222 & 1.914 & 0.489 \\
\hline \hline
\end{tabular}

Estimated Worth of Fuel Additions

The worth of the added fuel can be estimated by calculating the excess reactivity which would be present in a 56 -element core with 0.383 per cent $\Delta k / k$ excess (the initial Lead-Reflected Core arrangement) if all 56 elements had $404 \mathrm{~g}$ of uranium-235 rather than $303 \mathrm{~g}$. It is assumed that each of the elements is worth 0.50 per cent $\Delta \mathrm{k} / \mathrm{k}$ if added to the core perimeter. Therefore the addition of nine elements required to go from the 47 elements shown in Figure 7 to the 56 -element core of Figure 3 would be worth 4.50 per cent $\Delta \mathrm{k} / \mathrm{k}$. No correction to this figure is necessary to account for changes in excess reactivity in the critical configuration since it was the same in both cores. Thus, the estimated total worth of fuel added to the Lead-Reflected Core is 4.50 per cent $\Delta k / k$.

\section{Migration-Area Measurements}

The migration area was measured by the method described in BMI-1288. In this method the reactivity worth of water-height changes is used in conjunction with the onegroup criticality equation to estimate the migration area. The pertinent relation is

$$
\left(\frac{\partial \rho}{\partial h}\right)^{-1 / 3}=\left(\frac{k \propto}{2 \pi^{2} M_{/ /}^{2}}\right)^{1 / 3} \mathrm{H},
$$

where

$\frac{\partial \rho}{\partial h}=$ reactivity worth of water-height changes

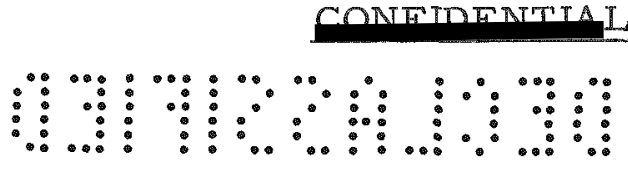


$k_{v e}=$ infinite multiplication constant

$M_{/ /}^{2}=$ migration area in the axial direction

$H=$ water height plus total extrapolation distance $=h+\lambda$.

Figure 8 gives the experimental values of $\rho$ versus $h$ for the $47-, 49-$, and $50-e l e m e n t$ cores. The least-squares values of $\partial \rho / \partial h$ derived from the curves are also shown.

The values of $(\partial \rho / \partial h)-1 / 3$ were plotted against $h$. The axial extrapolation distance was found by evaluating this relation at $\partial \rho / \partial \mathrm{h}=0$; this gave a value of $8.6 \mathrm{~cm}$. From the slope of the curve [ see Equation(1)] the value of $M \frac{2}{/ /} / k_{\infty}$ was found to be
$33.66 \mathrm{~cm}^{2}$.

The value of $\mathrm{M}_{/ /}^{2} / \mathrm{k}_{\alpha}$ given above resulted from changes in the axial geometric buckling. A corresponding value can be obtained by considering changes in the radial geometric buckling (changes in number of fuel elements or effective radius). The data taken by making only two radial changes probably do not give a reliable value for the radial migration area. Therefore these results are not given.

\section{Elux Measurements}

Measurements were made in this core to determine the axial and radial variation of the total and epicadmium neutron flux. For these measurements bare and 20 mil-thick cadmium-covered 0.033-in.-diameter manganese wires were inserted in the center mandrel of various fuel elements in the core. The axial flux distribution was measured in Positions 1 and 14 (see Figure 7). The radial distribution was measured $10 \mathrm{in}$. from the bottom of the fuel along two major diameters, $A A$ and $B B$, shown in Figure 7.

The results of the axial and radial llux-distribution measurements are given in Figures 9 and 10, respectively. In Figure 9. the total and epicadmium flux distributions are compared with corresponding ones from the Clean Core configuration (no lead reflector). * The axial flux distribution does not appear to be influenced by the increased fuel loading except in the lower axial reflector reglon. $*$ The cadmium ratio (total manganese-wire activity/cadmium-covered-wire activity) is reduced by the highex fuel loading as would be expected.

The radial flux distributions along the Radii $A A$ and $B B$ (Figure 10) differ from each other at equivalent distances from the center of the core. The difference probably results from the irregular shape of the core boundary in the critical arrangement (note Figure 7).

The Lead-Reflected Core data would be more desirable lor comparison since the Clean Core configuraulon contaned no lead reflector. However, anal flux distributions for the lead-reflected core are not avallable.

Water serves as the lower axial reflector, resulting in a flux peak in this reglon withu the element. The upper axial reflector is aluminum and causes no flux peaking in this region. 
$\therefore \ldots .$.

$\therefore \ldots:$ :

......

... $\therefore$ :

….

$\because \because \bullet$

$\because \because$

$\because \because$

$\therefore \cdots$

$\therefore$

$\therefore$

$\because \cdots 0^{\circ}$

$\vdots \ldots$

$\therefore$ …:
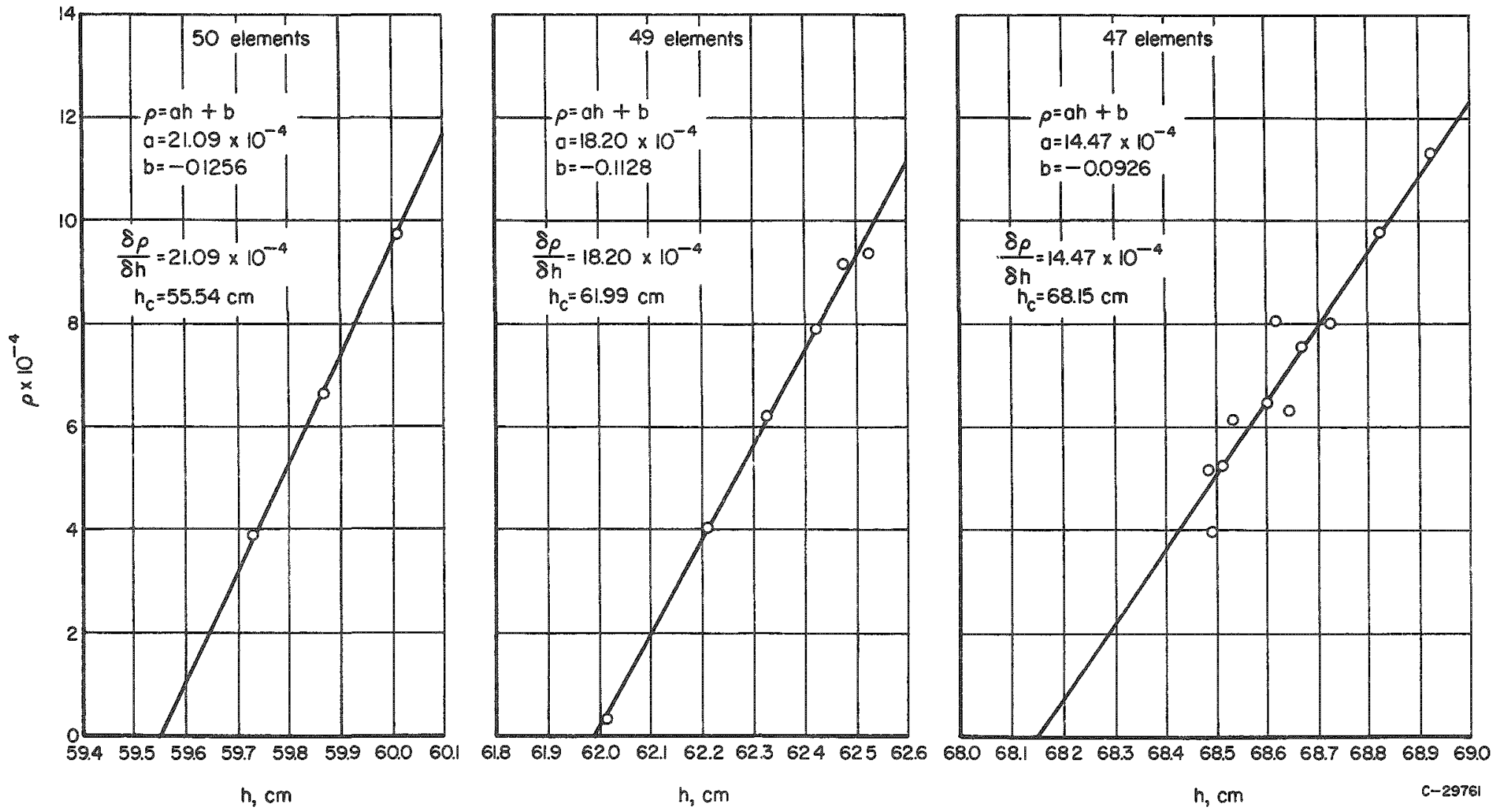

FIGURE \&. REACTIVITY VERSUS CORE HEIGHT FOR LEAD-REFLECTED CORE MODIFIED WITH ADDITIONAL FUEL LOADING 


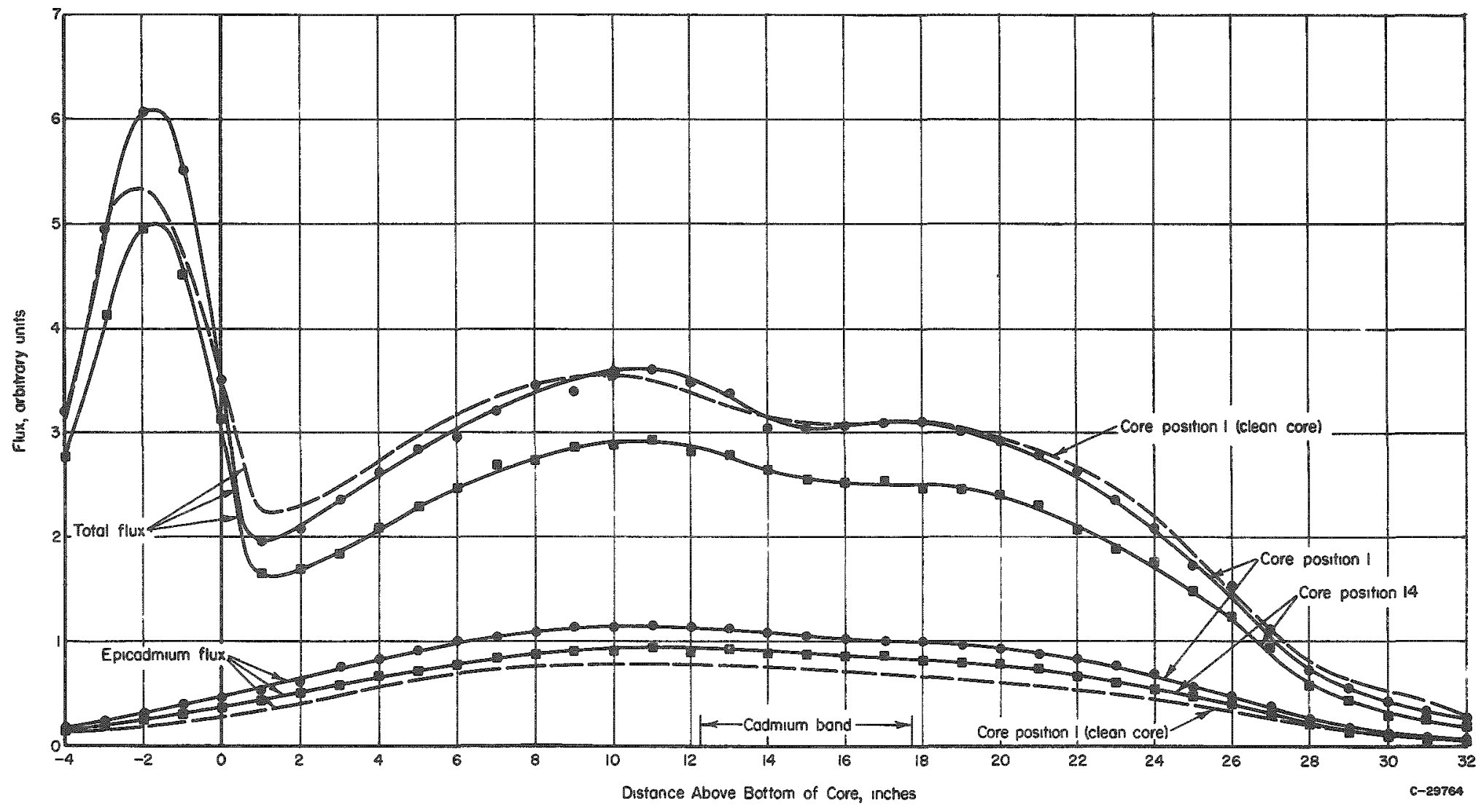

FIGURE 9. AXIAL FLUX DISTRIBUTIONS IN LEAD-REFLECTED CORE WITH MODIFIED FUEL LOADING

Data ontained with manganese-iron wires in cencer of indicated fuel elements. 
$\therefore . .$.

$\vdots . . \therefore$

.......

.....:

$\ldots . .$.

$\because \because$

$\because \because$

$\because \because{ }^{\circ}$

$\vdots . . .$.

$\therefore \circ$

$\therefore$ :.o: :

$\therefore$

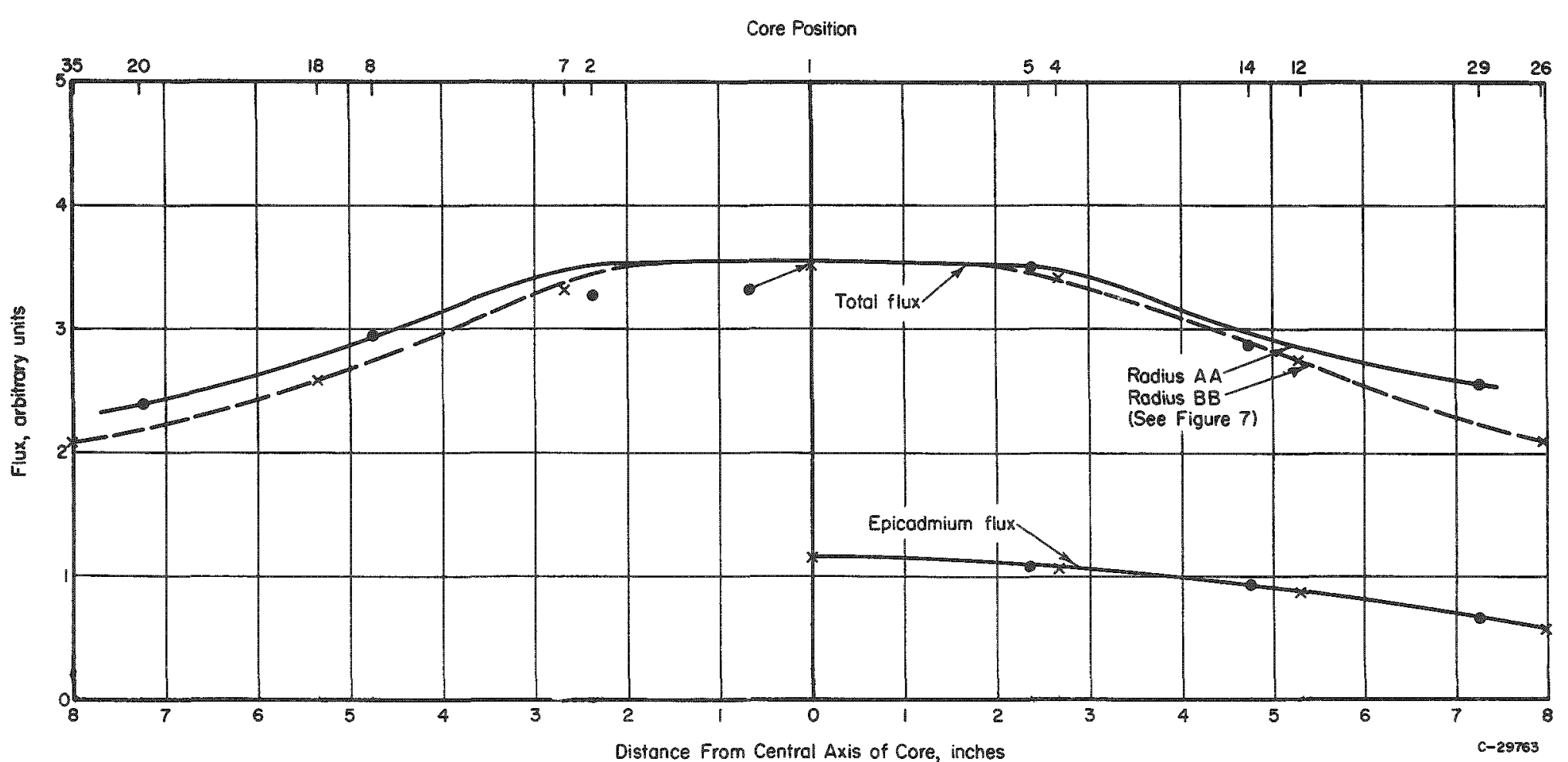

FIGURE 10. RADIAL FLUX DIS TRIBUTION IN LEAD-REF LECTED CORE WITH MODIFIED FUEL LOADING

Data obtained with manganese-iron wires in center of indicated fuel elements. 


\section{Thermal-Utilization Measurements}

The thermal utilization was determined for the center core element. The thermal-flux distribution was measured in detail within and adjacent to this fuel element at a position $10 \mathrm{in}$. above the bottom of the fuel for use in this determination.

The calculated value of the thermal urilization is 0.807 . Data pertinent to the calculations are shown in Tables 3 and 4.

\section{Lead Reflected Core - Modified Steel Content}

The original Lead-Reflected Core with $303 \mathrm{~g}$ of uranium-235 per element was modified by adding stainless steel to each of the fuel elements. This experiment investigated the conditions which might prevail if greater fuel-element thicknesses or lower volume per cent fuel loadings $\left(\mathrm{UO}_{2}\right.$ in stainless) were required.

Type 304 stainless steel was added to each fuel element by inserting 10 -milthick tubes, 2-1/2 ft long, within each of the four fuel cylinders. The tubes were located axially between the positioning spiders. The outside diameters of the added steel tubes were $0.495,0.705,0.905$, and $1.140 \mathrm{in}$. The total mass of steel added to each fuel element was about $385 \mathrm{~g}$.

\section{Critical Core Configuration}

The Lead-Reflected Core modified by the added stainless steel was critical with 58 fuel elements arranged as shown in Figure 11 . The core contained 17,675 g of uranium -235 and an excess reactivity of 0.075 per cent $\Delta \mathrm{k} / \mathrm{k}$.

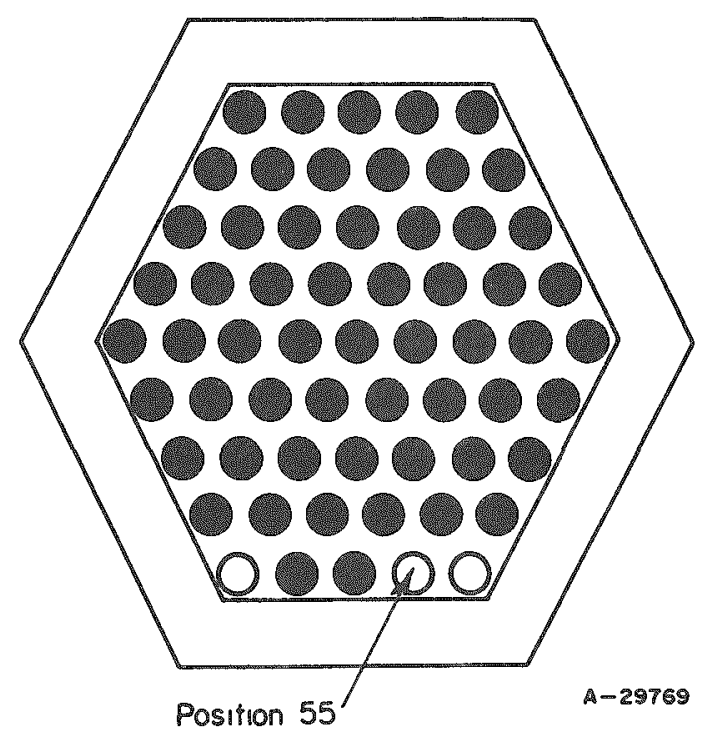

FIGURE 11. INITIAL CRITICAL CONFIGURATION IN LEAD-REFLECTED CORE MODIFIED WITH ADDITIONAL STAINLESS STEEL

58 fuel elements.

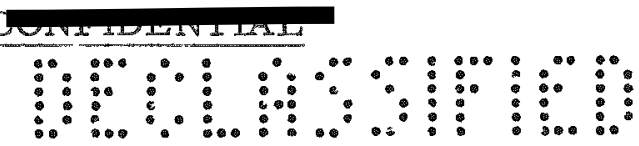


TABLE 3. PARAMETERS USED IN THERMAL-UTILIZATION CALCULATIONS

\begin{tabular}{|c|c|c|c|c|c|}
\hline \multirow[b]{2}{*}{ Cell Material } & \multirow{2}{*}{$\begin{array}{c}\text { Pex Cent of } \\
\text { Total Cell } \\
\text { Volume }\end{array}$} & \multirow[b]{2}{*}{$\begin{array}{c}\text { Ratio to } \\
\text { Fuel Volume }\end{array}$} & \multicolumn{2}{|c|}{ Cross Section } & \multirow{2}{*}{$\begin{array}{c}\text { Ratio to } \\
\text { Fuel } \\
\text { Cross } \\
\text { Section }\end{array}$} \\
\hline & & & $\begin{array}{l}\text { o(a) } \\
\text { barns }\end{array}$ & $\begin{array}{c}\sum \\
\mathrm{cm}-1\end{array}$ & \\
\hline Watex & 51.05 & 63.02 & 0.589 & 0.0196 & 0.000686 \\
\hline Aluminum & 9.83 & 12.14 & 0.204 & 0.123 & $0.00043 i$ \\
\hline Stainless steel & 8.63 & 10.65 & 2.66 & 0.2217 & 0.007764 \\
\hline Uranium -235 & 0.81 & 1.00 & $599(b)$ & 28.555 & 1.00 \\
\hline
\end{tabular}

(a) Corrected for Maxwellian distribution.

(b) Corrected for non-1/v dependence.

TABLE 4. THERMAL-UTILIZATION DATA

Calculated Value of Thermal Utilization, $f=0.807$.

\begin{tabular}{lcc}
\hline \hline & $\begin{array}{c}\text { Average Relative } \\
\text { Thermal Flux }\end{array}$ & $\begin{array}{c}\text { Ratio to Flux } \\
\text { in Fuel }\end{array}$ \\
\hline Uranium-235 & 4369 & 1.00 \\
Water & 14118 & 3.23 \\
Aluminum & 8560 & 1.96 \\
Stainless steel & 4743 & 1.08 \\
\hline
\end{tabular}

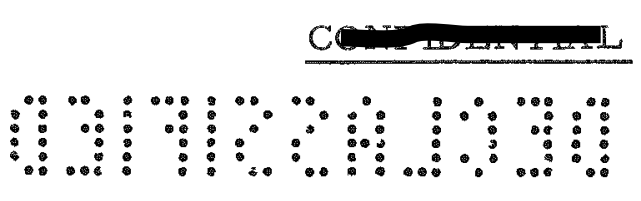


Reactivity Worth of Peripheral Fuel

Elements

A fuel element having the modified steel loading was added to Position 55, resulting in a 59-element core. The new fuel inventory was $17,958 \mathrm{~g}$, and the excess reactivity was 0.448 per cent $\Delta \mathrm{k} / \mathrm{k}$. Comparing this core with the critical core configuration above shows the element worth to be 0.373 per cent $\Delta k / k$.

Estimated Worth of Stainless Steel

Addition

The steel modifications were done after the fuel-modification experiments discussed earlier. It was therefore necessary to return the core elements to their original fuel loading (i.e., Lead-Reflected Core condition) prior to the steel addition. A check was made of the critical condition after this change was made. It was found that the Lead-Reflected Core was critical with 56 elements and had an excess reactivity of 0.435 per cent $\Delta k / k$. The difference in excess reactivity between this determination and earlier determinations is attributed to nonuniformities which again may have occurred in reassembling the fuel elements.

The change from the Lead-Reflected Core (above) to the core modified with steel additions required two extra fuel elements for criticality. However, the final cxcess reactivity in the core was less by 0.360 per cent $\Delta \mathrm{k} / \mathrm{k}$. Using a 0.373 per cent $\Delta \mathrm{k} / \mathrm{k}$ worth for each of the added elements, the resulting total shutdown worth of the stainless steel addition amounts to 1.106 per cent $\Delta \mathrm{k} / \mathrm{k}$.

\section{Uniform Radial Power Distribution Core}

In an attempt to improve the performance of the basic GCRE-1 design AerojetGeneral calculated a fuel-element spacing arrangement which was intended to flatten the radial power distribution. For the se calculations it was assumed that the fuelelement construction and core material composition were unchanged, and that the lead reflector was uniformly at a distance of $1 / 2 \mathrm{in}$. from the peripheral fuel elements.

The calculated fuel-element spacings for a symmetry sector and a sketch of the core are shown in Figure 12. The indicated symmetry sector is mirrored every 30 deg. The fuel-element lattices for the (calculated) Uniform Radial Power Distribution Core and the Lead-Reflected Core are compared in Figure 13. The moderator-tofuel ratio in the Uniform Radial Power Distribution Core increases with the radius. Compared with the constant value of this ratio for the Lead-Reflected Core, it is smaller in the central region and larger in the outer regions.

Examination of the calculated element spacings showed that some peripheral fuel elements would interfere with the lead reflector. Since further studies might require the reflector to be in the same position as in the Lead-Reflected Core, it was decided to adjust the fuel-element spacings rather than relocate the lead. The adjusted spacings are indicated by the dotted circles in Figure 12. This adjustment was necessary on two sides of the core and affected only ten elements. 


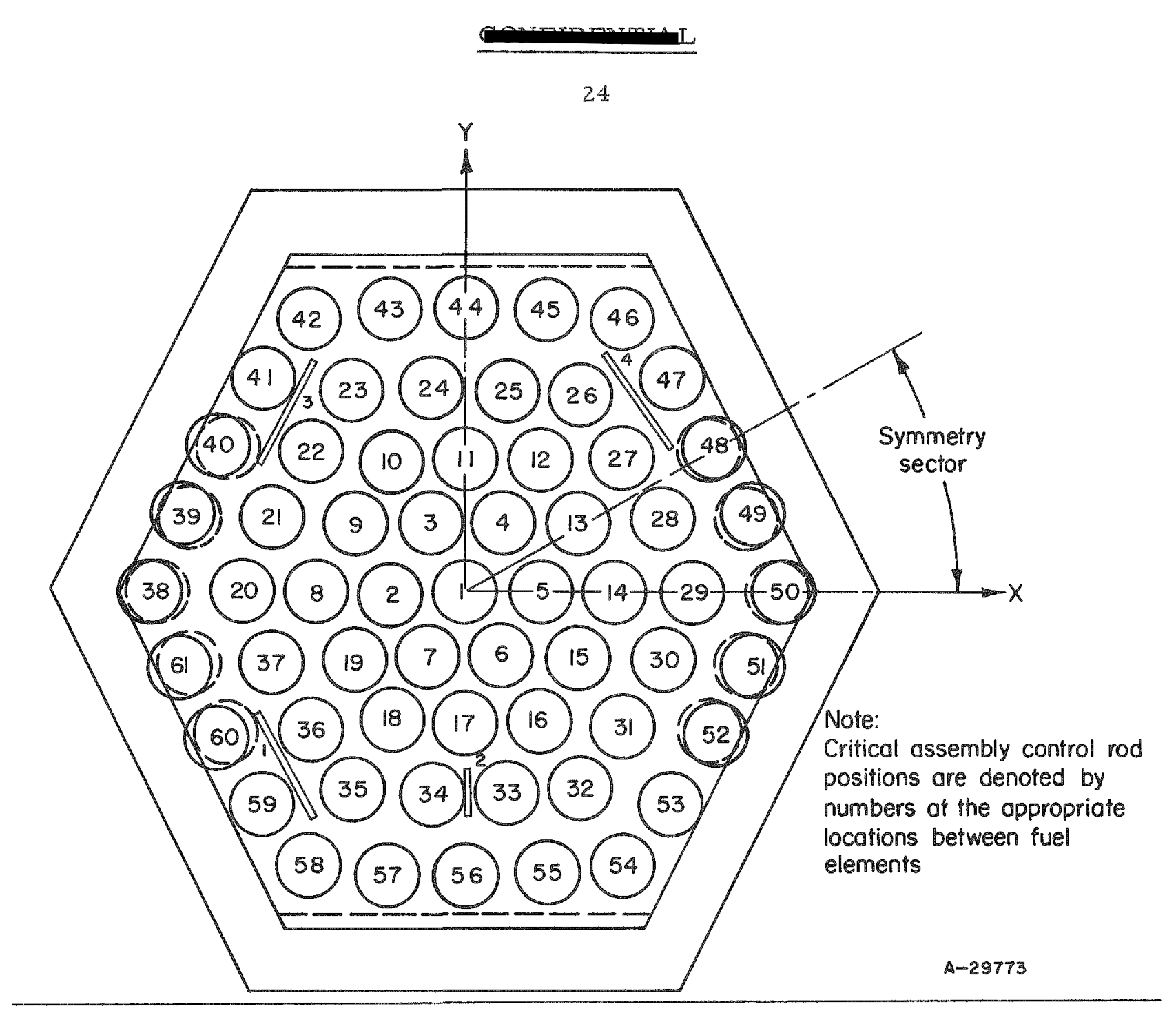

$\mathrm{X}-\mathrm{Y}$ COORDINATES FOR SYMMETRY SECTOR

\begin{tabular}{|c|c|c|c|c|c|}
\hline \multirow[b]{2}{*}{ Element Position } & \multicolumn{2}{|c|}{ Coordinate } & \multirow[b]{2}{*}{ Element Position } & \multicolumn{2}{|c|}{ Coordinate } \\
\hline & $\mathrm{X}$, in. & $\mathrm{Y}$, in. & & $\mathrm{x}$, in. & $\bar{Y}$, in. \\
\hline 1 & 0 & 0 & 13 & 3.52 & 2.03 \\
\hline 5 & 2.35 & 0 & 28 & 6.18 & 2.19 \\
\hline 14 & 4.70 & 0 & 48 & 7.80 & 4.50 \\
\hline 29 & 7.20 & 0 & 48 -displaced & 7.60 & 4.39 \\
\hline 50 & 10.00 & 0 & 49 & 9.00 & 2.29 \\
\hline 50-displaced & 9.77 & 0 & 49-displaced & 8.68 & 2.21 \\
\hline
\end{tabular}

FIGURE 12. FUEL-ELEMENT LATTICE SPACING FOR UNIFORM RADIAL POWER DISTRIBUTION CORE 


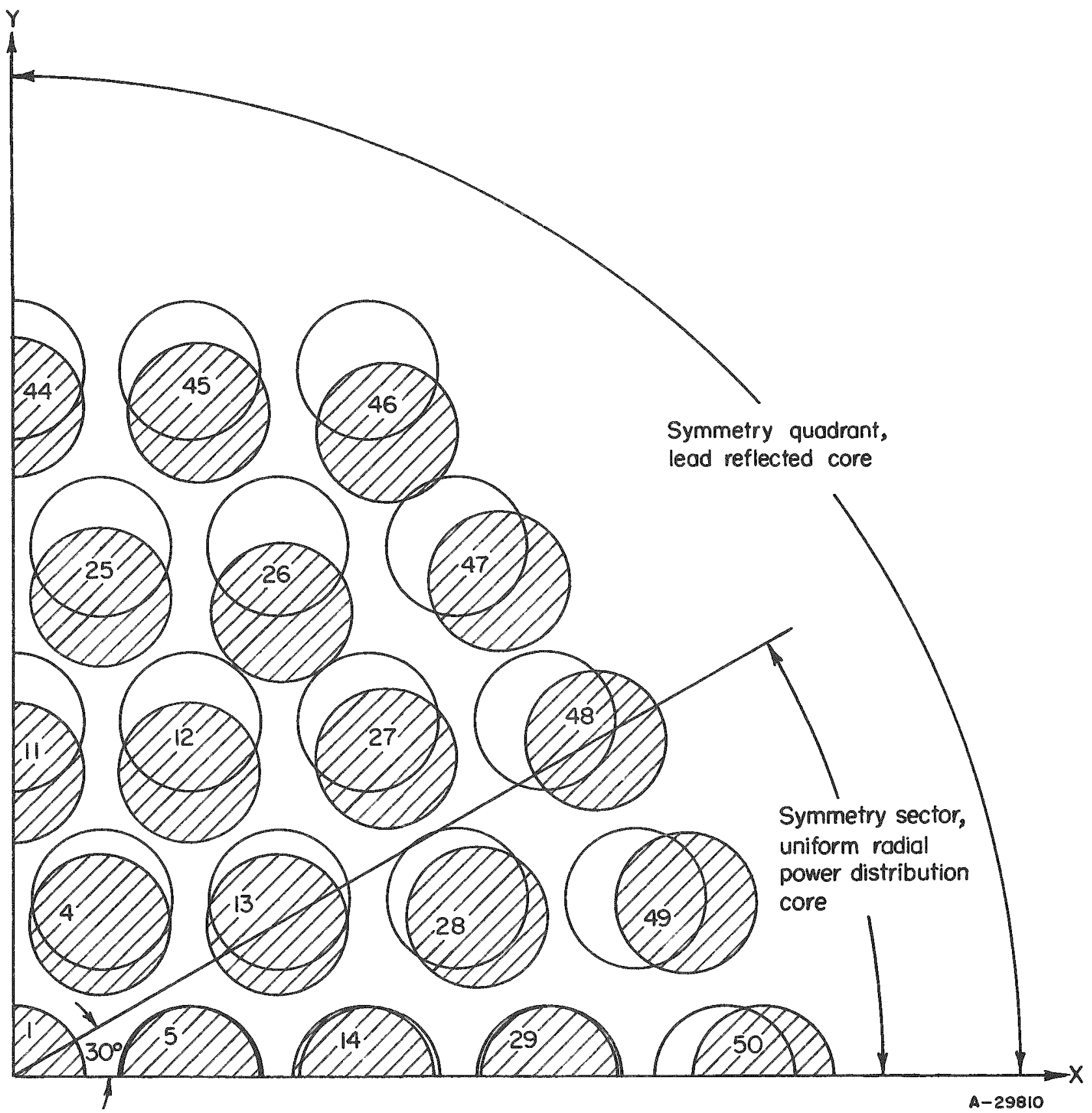

FIGURE 13. COMPARISON OF FUEL-ELEMENT LATTICES FOR THE, LEAD-REFLECTED AND CALCULATED UNIFORM RADIAL POWER DISTRIBUTION CORES

Shaded portions are those of the Uniform Radial Power Distribution Core.

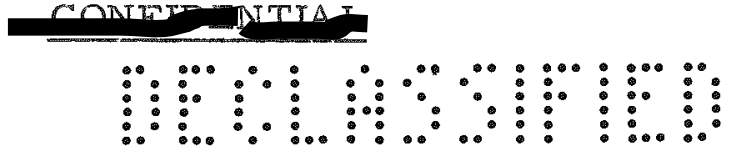




\section{6}

To duplicate the reflector configuration assumed in the calculations, $1 / 2 \mathrm{in}$. of lead was added to the front and back inner face of the reflector. The dashed lines (Figure 12) indicate where the lead was added. Experiments were carried out with the additional lead removed to evalule its effect on power flattening.

\section{Critical Core Configuration}

The Uniform Radial Power Distribution Core was critical with 57 fuel elements arranged as shown in Figure 14. This core contained 17,386 g of uranium-235 and an excess reactivity of 0.135 per cent $\Delta k / k$.

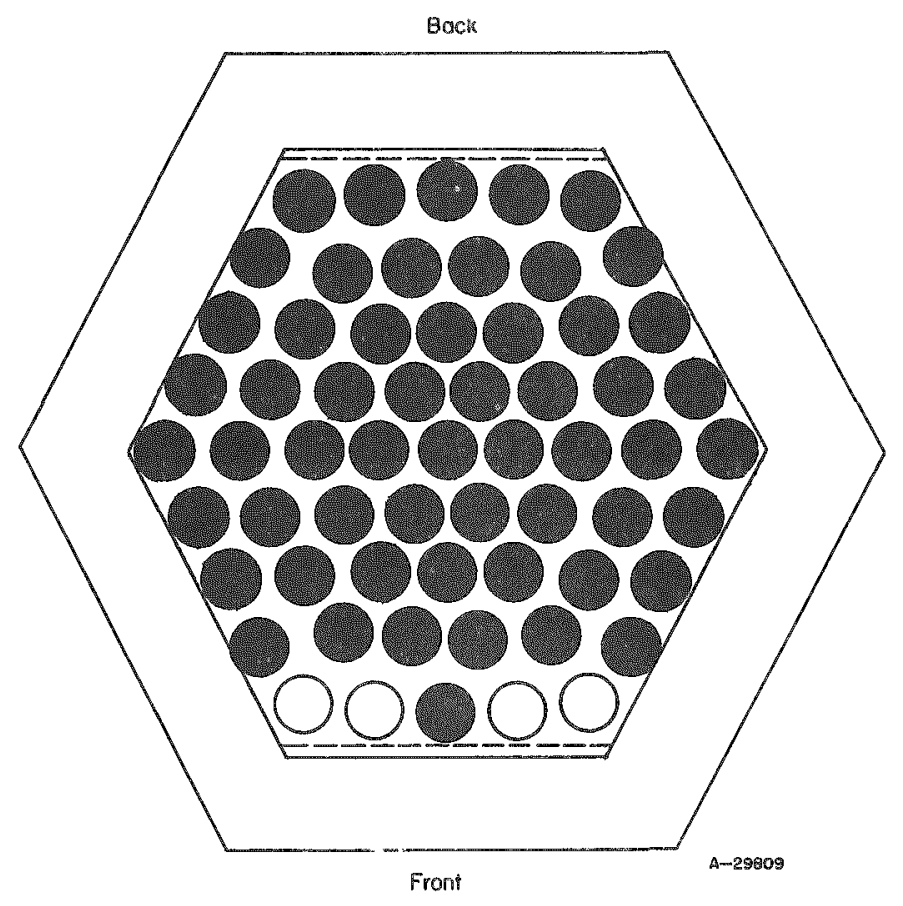

FIGURE 14. INITIAL CRITICAL CONFIGURATION IN UNIFORM RADIAL POWER DISTRIBUTION CORE

57 fuel elements.

\section{Power-Distribution Measurements}

Two groups of power-distribution measurements were made in this core. The first group was done in the elements in Positions 1, 3, 10, 11, 23, 24, 42, 43, and 44 , comprising a symmetry sector; the lead-reflector position for the se measurements is indicated by the dashed lines (Figure 12). Data were obtained in these same positions and in Positions 13, 28, and 48 in the second group of measurements. In the second measurements the additional 1/2-in. thickness of lead was removed, i.e., the lead-reflector position was as indicated by the solid lines.

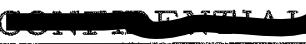


Measurements were made with catcher foils at locations 8 and 15 in. from the bottom of the fuel on the outer fuel cylinders of the specified elements. The catcher foils were placed in line with core radii. One foil was placed on the side of the fuel element facing the center of the core (called the front side in the subsequent discussion) and one on the side away from the center of the core (denoted the back side).

Figure 15 shows the results of the power-distribution measurements. The quantity, $P / \bar{P}$, is defined to be the ratio of the power developed at a given point to the core averaged power. The core average is evaluated as

$$
\overline{\mathbf{P}}=\frac{\sum_{i} \mathbf{P}_{i} N_{i}}{N}
$$

where

$$
\begin{aligned}
& N_{i}=\text { the number of elements of Type } i \text { in the core } \\
& N=\text { total number of elements in the core }=\sum_{i} N_{i} \\
& P_{i}=\text { measured catcher-foil activity in the } i \text { th element. }
\end{aligned}
$$

For comparison the corresponding data from the Lead-Reflected Core are also shown on Figure 15.

The data of Figure 15 include points from both groups of measurements mentioned previously. Only points taken along the two radii bounding the symmetry sector are presented. All measurements taken within the symmetry sector were used in evaluating the core averaged power according to Equation (2). In this evaluation, it was assumed that this symmetry sector is a representative sector from the core. Some asymmetry of the core is introduced by the critical core arrangement (note Figure 14) and by the ten displaced elements. But it is believed that these asymmetries are far enough removed from the "symmetry" sector used in evaluating $\bar{P}$ to justify this as sumption.

From the two groups of measurements it is possible to evaluate (1) the power flattening associated with the new lattice, (2) the local effect on power flattening of moving the lead radially outward, and (3) the local effect of displaced elements in Positions 48, 49, 50, etc.

A maximum value of the local power to core averaged power occurs in Position 11. Here the lattice spacing changes from a uniform hexagon (Positions 1 through 19) to a nonuniform one. Comparing these data with the Lead-Reflected Core data shows that changing lattice spacing reduces the maximum value of the ratio of local power to core averaged power from 1.46 to 1.24 . The data taken with the 1/2-in. lead slab removed show no improved power flattening.

Data taken in Position 48, one of the displaced positions, are included in Figure 15. The power-generation rate is considerably below that measured in Position 44 in the flux-symmetry sector. This is probably due more to the proximity of the lead reflector than to the displaced lattice position. 
$\therefore \cdots$

$\therefore$

$\ldots$

$\ldots \therefore:$

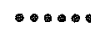

$\because \because$

$\because \because$

$\because \cdots$

$:$

$\because$

$\because \ldots$

$\therefore:$

…‥

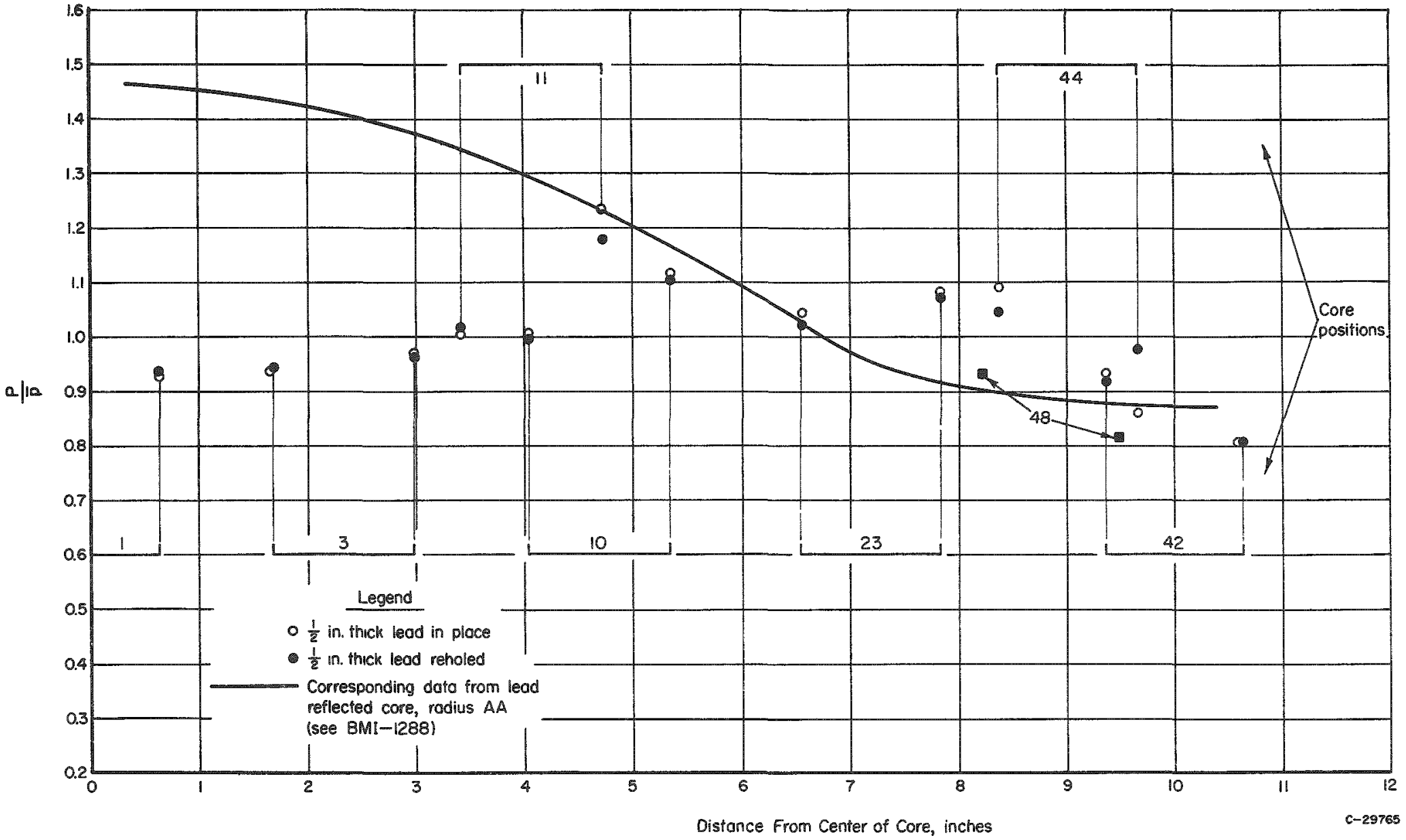

FIGURE 15. RADIAL POWER DISTRIBUTION IN UNIFORM RADIAI POWER DISTRIBUTION GORE

Data obtained with catcher foils on outer fuel cylinders of fuel elements in indicated core positions. 


\section{Flux-Distribution Measurements}

Measurements of the total and epicadmium neutron flux (using manganese wire activity) were made in the center of the fuel elements in Positions 1, 3, 10, $11,23,24$, 42,43 , and 44 (a symmetry sector) and Positions 12, 45, and 46. Axial distributions were obtained in Positions 1 and 46. Radial distribution data were taken 8 in. above the bottom of the fuel in all the positions. These measurements were made with the additional 1/2 in. of lead removed; the reflector is described by the solid lines of Figure 14.

The axial total and epicadmium flux distributions are shown in Figure 16. The data from Position 1 are compared with corresponding data from the Clean-Core configuration (described in BMI-1288). * No significant change in the shape of the axial flux distribution is noted. A decrease in the cadmium ratio is apparent which may result from the decreased moderator-to-fuel ratio in the central region of the Uniform Radial Power Distribution Core (note the change in lattice spacing in Figure 13). This is further borne out by the increased cadmium ratio measured in Position 46 where the moderator-to-fuel ratio is greater than in the Clean Core.

The radial total and epicadmium flux distributions are given in Figure 17. To indicate the extent of flux flattening the flux data are presented in the form $\phi / \bar{\phi}_{\text {total }}$, which is the ratio of the local flux to the core averaged total flux. Comparing these data with corresponding data from the Clean Core indicates that the change in lattice spacing, decreases the ratio of the maximum to average total flux from 1.37 to about 1.2. Furthermore, the maximum flux value occurs 4.5 in. out from the center of the core in the Uniform Power Distribution Core. Figure 17 indicates that the cadmium ratio increases in going from the center toward the core perimeter. The inset on Figure 17 shows the azimuthal variation of the flux at the perimeter of the core. Position 44 has a maximum flux relative to other peripheral positions.

\section{Thermal Utilization Measurements}

Detailed flux measurements for use in calculating thermal utilization were made in and about the fuel elements in Positions 1, 12, 32, and 45. The pertinent data and the calculated values of thermal utilization are presented in Tables 5 and 6 . Figure 18 shows the change in the thermal utilization with radius. Caution must be exercised in using this curve for estimating the thermal utilization at other core radii since the measurements were not made on a single core radius** and since the element in Position 32 is at the effective core perimeter because of the asymmetric core loading required for criticality (note Figure 14).

\footnotetext{
See footnote page 17.

If Position 26 had been available a more nearly correct radial distribution of thermal utilization could have been obtained. However, the manganese-wire holders used in the flux measurements in Positions 12 and 26 would have overlapped. Other symmetric core positions which might have been used with the wire holder designed for Position 26 are Positions 20, 23, 29, 32, and 35. However, since Positions 20 and 29 were unsuitable because of possible influence from the displaced elements in Positions 38, 50, etc. and since the control blades interfered with Positions 23 and 35 , only Position 32 was available for measurements at this radius.
}

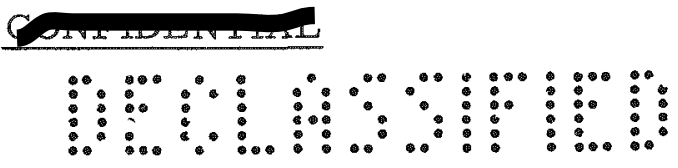




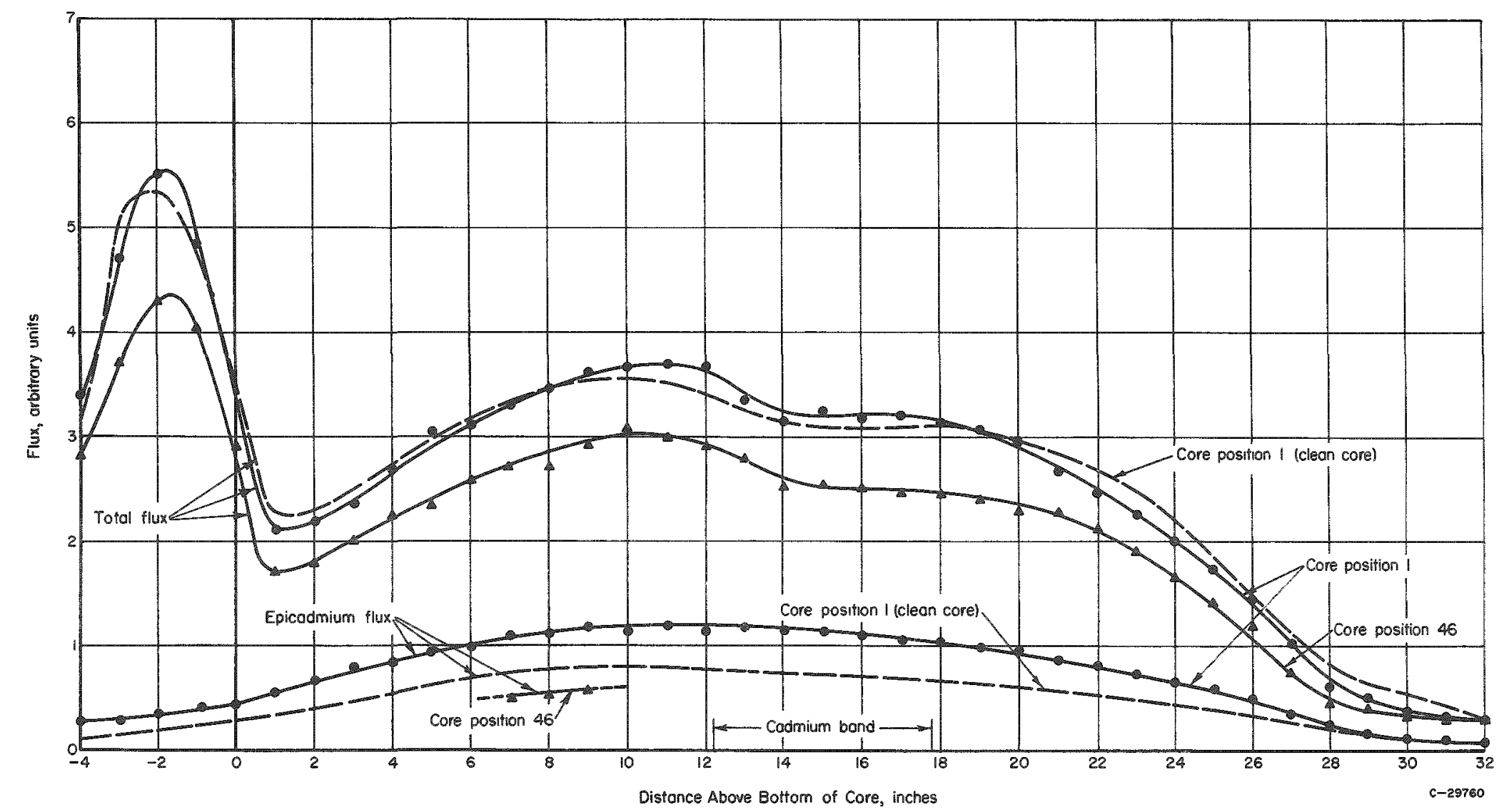

FIGURE 16. AXIAL FLUX DISTRIBUTION IN UNIFORM RADIAL POWER DISTRIBUTION CORE

Data obtained using manganese-iron wires at center of fuel elements in indicated core positions. 


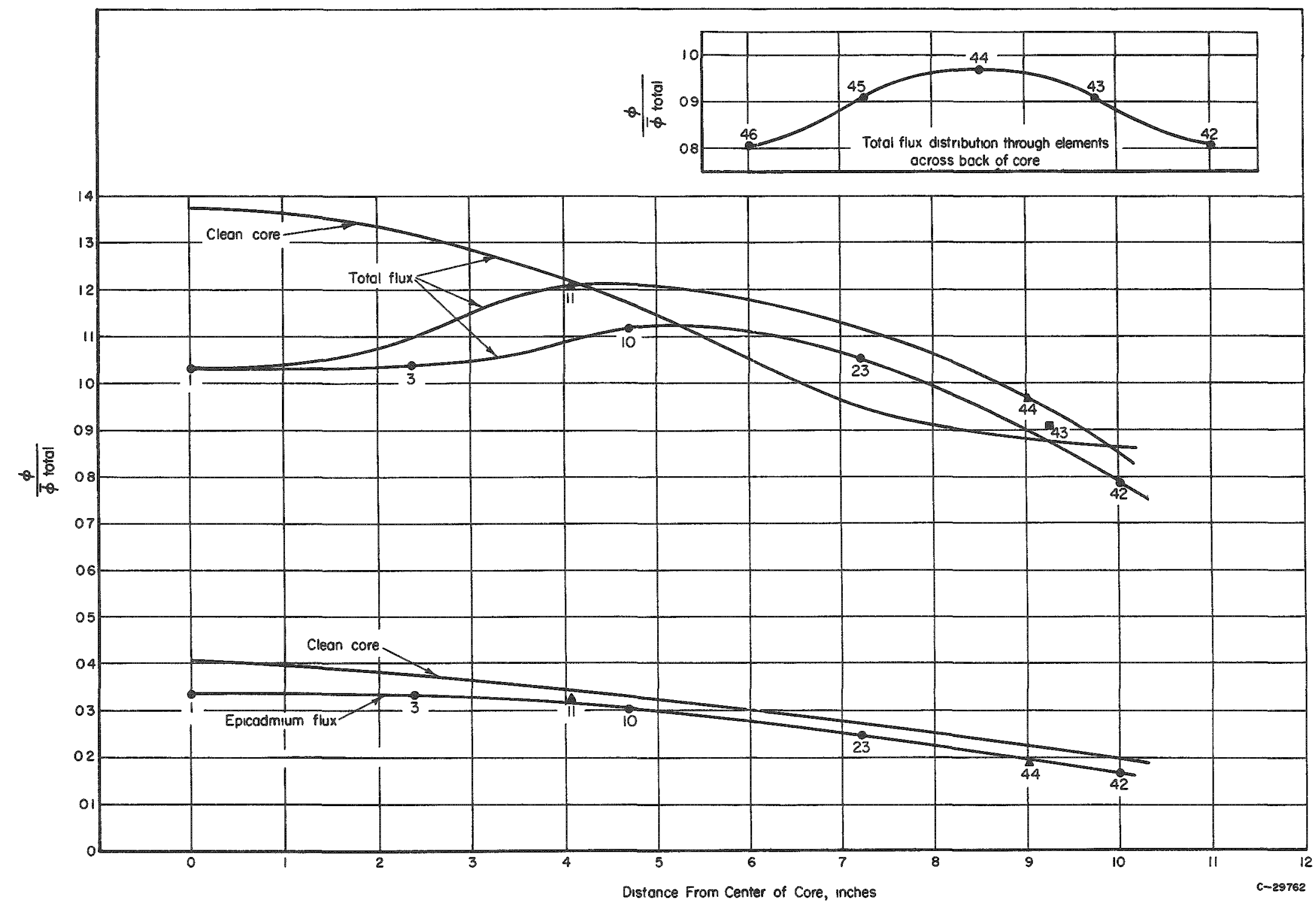

FIGURE 17. RADIAL FLUX DISTRIBUTION IN UNIFORM RADIAL POWER DISTRIBUTION CORE

Data obtained using manganese-iron wires at center of fuel elements in indicated core positions. 
TABLE 5. PARAMETERS USED IN THERMAL-UTILIZATION CALCULATIONS(a)

\begin{tabular}{|c|c|c|c|c|}
\hline & Position 1 & Position 12 & Position 32 & Position 45 \\
\hline \multicolumn{5}{|c|}{$\begin{array}{l}\text { Amount of Indicated Material } \\
\text { in Total Cell Volume, per cent }\end{array}$} \\
\hline Moderator & 42.49 & 48.31 & 54.45 & 59.70 \\
\hline Aluminum & 11.55 & 10.38 & 9.15 & 8.09 \\
\hline Stainless Steel & 10.13 & 9.11 & 8.03 & 7.10 \\
\hline Uranium -235 & 0.71 & 0.67 & 0.57 & 0.52 \\
\hline \multicolumn{5}{|c|}{$\begin{array}{l}\text { Ratio of Material Volume to } \\
\text { Fuel Volume }\end{array}$} \\
\hline Moderator & 59.84 & 72.10 & 95.53 & 114.80 \\
\hline Aluminum & 16.27 & 15.49 & 16.05 & 15.55 \\
\hline Stainless Steel & 14.27 & 13.60 & 14.09 & 13.65 \\
\hline Uranium -235 & 1.00 & 1.00 & 1.00 & 1.00 \\
\hline
\end{tabular}

(a) Cross-section data are given in Table 3.

TABLE 6. THERMAL-UTILIZATION DATA

\begin{tabular}{|c|c|c|c|c|}
\hline & Position 1 & Position 12 & Position 32 & Position 45 \\
\hline \multicolumn{5}{|l|}{$\begin{array}{l}\text { Average Relative Thermal Flux } \\
\text { in Indicated Material }\end{array}$} \\
\hline Uranium -235 & 3,686 & 4,035 & 3,856 & 3,688 \\
\hline Moderator & 8,845 & 10,801 & 10,558 & 11,530 \\
\hline Aluminum & 5,969 & 6,744 & 6,316 & 6,245 \\
\hline Stainless Steel & 3,947 & 4,243 & 4,106 & 3,955 \\
\hline \multicolumn{5}{|l|}{$\begin{array}{l}\text { Ratio of Flux in Material to } \\
\text { Flux in Fuel }\end{array}$} \\
\hline Uranium -235 & 1.00 & 1.00 & 1.00 & 1.00 \\
\hline Moderator & 2.40 & 2.68 & 2.74 & 3.13 \\
\hline Aluminum & 1.62 & 1.67 & 1.64 & 1.69 \\
\hline Stainless Steel & 1.07 & 1.05 & 1.06 & 1.07 \\
\hline $\begin{array}{l}\text { Calculated Values of Thermal } \\
\text { Utilization }\end{array}$ & 0.811 & 0.797 & 0.766 & 0.730 \\
\hline
\end{tabular}




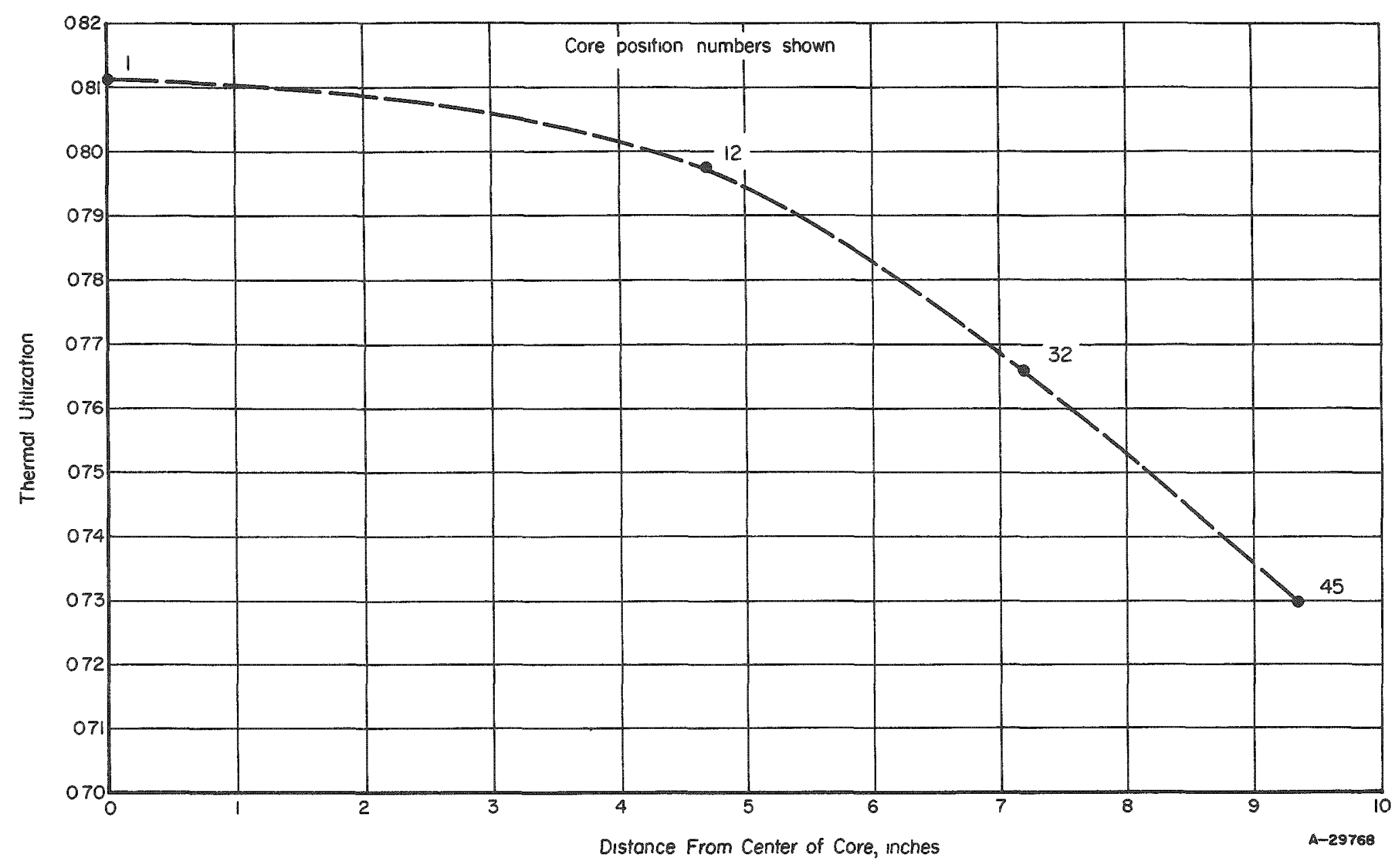

FIGURE 18. THERMAL UTILIZATION VERSUS RADIUS IN UNIFORM RADIAL POWER DISTRIBUTION CORE 


\section{SUMMARY}

Four major experiments with the GCRE Critical As sembly were done since Battelle issued BMI-1288. These were (1) an investigation of the effect of changes in axial reflector materials, (2) measurements of the reactivity effect and power distortion caused by fast safety control-blade guides, (3) evaluation of the effect of changes in the fuel-element material composition, and (4) investigation of a fuel-element distribution designed to produce uniform radial power-generation rates. These experiments were done with a 4 -in. -thick lead reflector located at the core perimeter.

The normal 2-3/4-in. - thick aluminum upper axial reflector was replaced by air, steel, and a combination of aluminum and steel $(2-3 / 4$ in. aluminum immediately adjacent to the core with $2-3 / 4$ in. steel above this). The results are summarized in Table 7.

TABLE 7. REACTIVITY WORTH OF UPPER AXIAL REFLECTOR MATERIALS

\begin{tabular}{lc}
\hline \multicolumn{1}{c}{ Material } & $\begin{array}{r}\text { Reactivity } \begin{array}{c}\text { Worth, } \\
\text { per cent } \Delta \mathrm{k} / \mathrm{k}\end{array} \\
\text { Void }\end{array}$ \\
Aluminum & $0.000^{(\mathrm{a})}$ \\
Steel & 0.175 \\
Aluminum and steel & 0.414 \\
\hline \hline
\end{tabular}

(a) Void is used as a basis for material worths.

Mock-up safety-blade guides were inserted into the core as indicated in Figure 4. The combined worth of the two guides was -0.281 per cent $\Delta k / k$. The power dis tortion caused by the guides was localized to elements immediately adjacent to them. In these elements only the side facing the guides was perturbed. The greatest perturbation due to the guides occurred in elements adjacent to the tips of the guides where a relatively large supporting structure is present.

Changes in the fuel-element composition included both fuel and stainless steel additions. A change in the fuel content from the core average value of $303 \mathrm{~g}$ to $404 \mathrm{~g}$ per fuel element resulted in a 47-element critical configuration. Based on the initial Lead-Reflected Core, the additional fuel was worth approximately 4.5 per cent $\Delta \mathrm{k} / \mathrm{k}$. The measured migration area for the 47 -element core was $33.7 \mathrm{~cm}^{2}$ and the thermal utilization 0.807. Axial flux measurements indicated no significant change in the axial flux distribution caused by the fuel additions. An increase in stainless steel from $1708 \mathrm{~g}$ to $2093 \mathrm{~g}$ per fuel element resulted in a shutdown reactivity worth of approximately 1.1 per cent. 
35 and 36

With a fuel-element distribution designed for uniform radial power distribution the core (surrounded by the 4 -in. -thick lead reflector) was critical with 57 fuel elements. The radial power distribution was flattened. The maximum to average (weighted) radial power was 1.24. This compares to the previous value of 1.46 present in the Lead-Reflected Core. The thermal utilization was measured as a function of radial location of the fuel elements. These results are given in Table 8.

TABLE 8. THERMAL-UTILIZATION VALUES IN THE UNIFORM POWER. DISTRIBUTION CORE

\begin{tabular}{cc}
\hline \hline Radial Position of & \\
Fuel Element, in. & Thermal Utilization \\
\hline 0 & 0.811 \\
4.2 & 0.797 \\
7.20 & 0.766 \\
9.25 & 0.730 \\
\hline
\end{tabular}

A check was made to determine whether the power could be made more uniform by removing a portion of the lead reflector (i.e., increasing the radial gap between the core perimeter and the lead reflector). Moving the reflector proved not to be significant for the conditions tested.

DAD:WCB:RAE:FJJ:JW C/mrm 